\title{
BONDING BETWEEN CELLULOSIC FIBERS IN THE ABSENCE AND PRESENCE OF DRY-STRENGTH AGENTS - A REVIEW
}

\begin{abstract}
Martin A. Hubbe
Various hydrophilic polyelectrolytes, including cationic starch products, are used by papermakers to promote inter-fiber bonding and increase paper's dry-strength. Thus, papermakers can meet customer requirements with a lower net cost of materials, more recycled fibers, or higher mineral content. In the absence of polymeric additives, key mechanisms governing bond development between cellulosic fibers include capillary action, three-dimensional mixing of macromolecules on facing surfaces, conformability of the materials, and hydrogen bonding. Dry-strength additives need to adsorb efficiently onto fibers, have a hydrophilic character, and have a sufficiently high molecular mass. Though it is possible to achieve significant strength gains by optimal usage of individual polyelectrolytes, greater strength gains can be achieved by sequential addition of oppositely charged polyelectrolytes. Superior strength can be achieved by in-situ formation of polyelectrolyte complexes, followed by deposition of those complexes onto fiber surfaces. Polyampholytes also hold promise as efficient dry-strength additives. Opportunities for further increases in performance of dry-strength agents may involve fiber surface modification, self-assembled layers, and optimization of the dry film characteristics of dry-strength polymers or systems of polymers.
\end{abstract}

Keywords: Dry strength, Adhesion, Bonding, Polyelectrolytes, Polyampholytes, Cationic starch, Cellulosic fibers, Paper, Polyelectrolyte complexes, Surface modification

Contact information: Department of Forest Biomaterials Science and Engineering, North Carolina State University, Campus Box 8005, Raleigh, NC 27695-8005 USA; hubbe@ncsu.edu

\section{INTRODUCTION}

Glue is not required in order to make a sheet of paper. This is one of the lessons that schoolchildren learn when they are fortunate enough to take part in a hands-on demonstration of papermaking. Usually the first step involves tearing sheets of paper into scraps and adding them to water in a blender. Subsequently, the suspension of fibers is formed into a new sheet of paper, pressed, and then dried by evaporation. The young papermaker leaves with a newly recycled sheet, taking advantage of a unique ability of cellulosic fibers to adhere to each other when they are dried while in contact.

This review considers a variety of chemical strategies that can be used in an effort to make a good thing better, by strengthening the inter-fiber bonds. The great majority of such strength-enhancing treatments are fully compatible with the recyclable nature of papermaking fibers (Zhang et al. 2002). The diversity of bonding agents, as well as the circumstances under which they are found to be effective, provide a viewpoint from which to better understand the surfaces of the fibers themselves. The goal of this review 
is to highlight strength-enhancement strategies that tend to increase the value of paper products, while at the same time help to minimize the environmental impact of papermaking operations.

\section{Why Enhance Bonding?}

Expressed in terms of function, the three main categories of paper or paperboard product can be classified as "packaging," "printing and writing," and "absorbing and wiping." Though paper within each of these categories can benefit from enhanced interfiber bonding, the manner in which such bonding benefits the product can differ.

Packaging paper and paperboard grades require sufficient strength to contain and protect various contents. For example, a corrugated box must have sufficient edge crush resistance (Seth et al. 1979; Fellers 1983) to support high loads when the boxes are stacked. Theoretical studies suggest that edgewise compressive failure of corrugated containers often involves delamination at points of high shear stress within the linerboard (Sachs and Kuster 1980; Fellers 1983). Thus, it is not surprising that edgewise compression strength can be improved by the use of dry-strength agents (Smith 1992). Though inter-fiber bonding also can be increased by refining (Seth et al. 1979; Paulapuro and Thorp 1983), the resulting internal delamination of individual fibers makes them less able individually to bear compressive loads. Refining also tends to decrease the rate at which water can be removed from the wet web of paper, limiting the rate of production. Thus, a promising approach is to add a polyelectrolyte, such as cationic starch, to enhance bonding (Moeller 1966; Harvey et al. 1973; Greif and Gaspar 1980; Hofreiter 1981; Howard and Jowsey 1989; Ghosh 1994; Alince et al. 1990; Formento 1994). Compressive strength also can be increased by papermaking technologies involving high wet-press pressures or dwell times (Smith 1992; Worsick 1994; Slater 2003), or drying the sheet continuously while it is under constraint (Kunnas et al. 1993; Retulainen 2003).

There are several ways in which manufacturers of containerboard products can convert strength enhancement into cost savings. One way is by reducing the weight of the product. Changes in the ways that linerboard is specified for shipping containers have allowed papers to reduce the weight of their product, as long as it still meets strength requirements (Gutmann et al. 1993). In other cases, papermakers can use lower quality fibers, having a lower price. Chemical additives can play a role in keeping the strength high enough to meet product requirements (Reynolds and Wasser 1980; Smith 1992). In addition, there is always a trade-off between what one pays as energy input for refining $v s$. the expense of dry-strength additives. Increases in one of these expenses tend to be offset the by reductions in the other expense.

To cite another example, consumers often judge the quality of milk cartons by their resistance to bulging. A package that appears to be bloated makes the consumer suspicious that the contents of the package may have spoiled. If, indeed, there is pressure build-up due to fermentation within the container, then the problem is beyond salvaging by means of paperboard strength. In other cases a suitably high stiffness will ensure that a carton doesn't bulge excessively. Because stiffness, according to the simplest theory (Kajanto 1998), is proportional to the cube of thickness of a material, the papermakers have an incentive to maintain a low density of the paperboard material. Excessive refining should be avoided, minimizing the tendency for fibers to flatten into ribbons and 
conform to each other in bonded areas. Again, dry-strength chemicals can help to compensate for the reduced inter-fiber bonding, when refining is reduced (Chan 1976).

Printing and writing papers can have different requirements, depending on the converting and printing operations for which they are designed. Offset lithography, one of the most important printing processes, places high demands on paper's surface strength and resistance to delamination. High levels of ink tack are required to achieve high fidelity of multi-color imaging. Though it would be technically possible to obtain the needed internal bonding strength by refining alone, while still maintaining the needed opacity, the most economical results usually can be achieved by a combination of refining and chemical additives (Tanaka et al. 2001). Use of cationic starch, for instance, can compensate for the lower bonding ability associated with recycled kraft fibers (Strazdins 1984; Hipple 1991; Nazhad and Pazner 1994; Zhang et al. 2002). Drystrength additives also help to compensate for the debonding effect of mineral fillers, which are added in order to achieve brightness and opacity specifications (Lindström and Florén 1984; Alince et al. 1990). Strength gains can be achieved with little sacrifice of opacity, especially if acrylamide-type strength resins are used (Farley 1987). In addition to chemicals added to the fiber furnish, papermakers usually add relatively large amounts of starch solution to the paper surface, in a so-called size-press operation (Ecklund 1989).

Xerographic copy papers, though similar to uncoated offset papers in many ways, present some different requirements. To pass successfully through copiers at high speed, with a minimum of jamming, copy paper needs to be relatively stiff, with a low tendency to curl. Again, due to the dependency of stiffness on the third power of the paper's thickness (or caliper), papermakers avoid measures that would excessively densify the paper. Large amounts of cationic starch, often in the range of 0.5 to $1.5 \%$ of the total product mass are usually added to the papermaking furnish in order to meet various strength specifications (Harvey et al. 1973; Formento et al. 1994).

Absorbent paper products, such as tissue and towel, represent the opposite of typical packaging products in terms of density. In order to maximize the amount of fluid that can be held in the product during its use, there is a critical need to maintain relatively large air-filled spaces among the fibers in the structure. At the same time, the paper needs to be strong enough to run efficiently through various manufacturing and converting processes. In many cases the papermaker's preferred option is to minimize the amount of refining, maintaining the initial relatively stiff, tube-like nature of the fibers. When using recycled fibers obtained from production with bleached kraft pulp, the history of drying tends to stiffen the fibers, making them less conformable (Scallan and Tigerström 1992; Nazhad and Pazner 1994; Dulemba et al. 1999; Hubbe et al. 2003b). The bulky nature of the resulting paper tends to be desirable, from the standpoint of tissue production. On the other hand, many recycled kraft fibers already have been subjected to extensive refining, tending to produce a relatively dense sheet of paper. In an attempt to thread the needle among various competing goals, papermakers often use combinations of seemingly incompatible additives. Dry-strength agents can be used to meet the strength requirements of the product. Meanwhile, debonding agents can be used to maintain the desired bulky nature of the paper (Conte and Bender 1992; Poffenberger et al. 2000). The mechanisms by which these two contrasting types of additives interact are not well known, and this is likely to be an interesting area of research. It is possible 
that debonding agents remain localized in patches on fiber surfaces, creating areas in which the fibers remain unbonded.

Trends in both packaging and printing grades point in the direction of increasing demands for more effective dry-strength treatments. Viewed over a span of years, almost every grade of paper or paperboard, for a given application, tends to decrease in basis weight. Lower weight yields savings not only with respect to the amount of materials needed for a given area of paper or paperboard product, but also due to lower costs of shipping and mailing. At the same time, filler levels tend to rise year by year. Filler particles interrupt inter-fiber bonding, and their surfaces are not conformable. Factors tending to favor increasing filler levels include their low cost, relative to fibers, and their contribution to opacity and brightness. In addition, there has been a trend towards greater use of fibers that are known to have less capability of inter-fiber bonding, e.g. high-yield mechanical pulps, and recycled office waste, and containerboard fibers. The trends just mentioned suggest that the main dry-strength strategies used by today's papermakers are likely to be sufficient to meet tomorrow's dry-strength goals. On the one hand, papermakers will continue to rely on refining and cationic starch to enhance dry strength. In addition, one can anticipate a need for innovative dry-strength additives, as well as a need to better understand how their effects can be optimized.

Each of the trends mentioned above has the potential to reduce the amount of newly pulped cellulosic fibers required to meet market demands for paper products. As will become clear in later sections of this report, commonly used dry-strength additives for addition to the papermaking furnish are generally non-toxic, biodegradable, and efficiently retained in paper during the manufacturing process. To set the context for discussing the effects of dry-strength additives, the following section describes some basic issues related to the development of adhesion between untreated cellulosic fibers that are dried in contact with one another.

\section{BONDING BETWEEN UNTREATED CELLULOSIC FIBERS}

\section{Got Contact?}

No contact, no bonding. If one assumes that hydrogen bonding between fibers plays a critical role in paper strength (Campbell 1959; Davison 1980; Fowkes 1983; Nissan et al. 1985; Tiberg et al. 2001), then it is necessary to assume that the at least parts of the facing surfaces can approach each other within about $0.27 \mathrm{~nm}$ (Linhart 2005). Distances associated with London dispersion forces are more forgiving (Hiemenz and Rajagopalan 1997; Lindström et al. 2005), but still, in order to explain development of significant inter-fiber bonding, one must assume contact within molecular dimensions.

Cellulosic fiber surfaces are rough on a scale of 0.01 to $10 \mu \mathrm{m}$. Studies of the refined kraft fibers indicate the presence of a wide range of fibrils and microfibrils extending outwards from the fiber surfaces (Clark 1985a,b; Neuman 1993; Pelton 1993, 2004). Dimensions can range from about $2-5 \mathrm{~nm}$ in the case of primary microfibrils (Fujita and Harada 2000) to much larger fibrils resulting from partial delamination of the outer layers of the cell wall. Roughness can severely reduce molecular contact between adjacent surfaces, depending on the scale and the material properties (Thomas 1999). 
Figure 1 shows two ways to represent the effect of roughness between cellulosic fibers in the wet state. Part A of the figure might be considered as a conventional view, in which roughness involves a series of indentations and asperities relative to a planar surface. The illustration in part B of the figure assumes that fibrils and microfibrils, which are directed outwards from the fiber surfaces in the wet state, play a major role with respect to inter-fiber contacts between wet fibers.

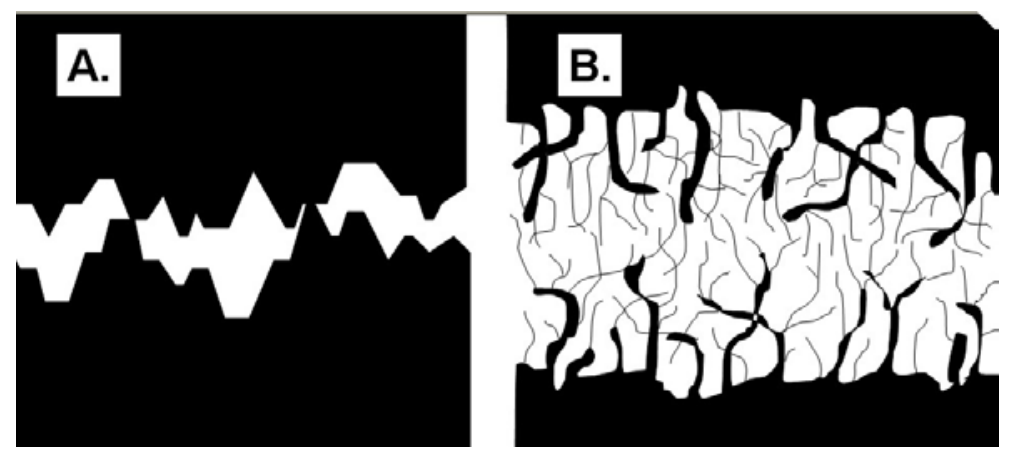

Fig. 1. Contrasting schematic concepts of contact between real solid surfaces. A: Conventional view. B: Fibrillated surfaces in the wet condition.

In light of fibers' roughness, one is forced to conclude either of two things with respect to the development of inter-fiber bonding. On the one hand, one might conclude that actual molecular contact between fibers within paper is highly inefficient on a molecular level, but somehow it is still sufficient to meet the needs of papermakers. Based on this view, it might be expected that there are tremendous opportunities to improve paper strength by suitable treatment or processing. On the other hand, one might assume that there is a mechanism by which fiber surfaces efficiently become drawn into molecular contact during the ordinary processes of papermaking. Based on this second view, it would make sense to explore ways in which dry-strength additives can further improve the efficiency of the process of bond formation as water is evaporated from paper. Two principles mechanisms appear to be mainly responsible for this "drawing together," and they will be discussed in the following two subsections.

\section{Capillary Forces}

Sandcastles provide a mundane example of capillary forces at work. Those who build sandcastles learn almost immediately that three phases - solid, liquid, and gas - all need to be present in order to build a successful castle. Attempts to build with dry sand are abandoned almost immediately in favor of damp sand, as a young builder settles into her or his activity. Attempts to build a castle under water can be even more futile, since the sand grains lack adhesion, and it is more difficult to view one's handiwork. By contrast, damp sand can be fashioned into a fantasy word. Such a castle can stand on its own, at least until the last films of water between the grains of sand are able to evaporate.

In addition to explaining the strength of sand castles, capillary forces also can account for the ability of wet paper to withstand significant tensile loads even before it has been dried. As noted by Lyne and Gallay (1954), the capillary forces within a damp sheet of paper tend to pull adjacent fibers towards one another. Depending on the 
coefficient of friction between those fibers, in the wet state, the forces normal to the plane of the sheet becomes translated into considerable strength within the plane of the sheet. Such a mechanism has been demonstrated in cases of paper made from glass fibers. Sheets formed from untreated glass fibers have almost no strength after drying (Lyne and Gallay 1954; Hubbe 2005), due to the inefficient contact between the stiff, rounded surfaces. Maximum tensile strength of the damp glass sheets was observed at a solids content of 20-25\% (Lyne and Gallay 1954).

Campbell $(1947,1959)$ was the first to employ similar reasoning to explain the development of paper strength during drying. An estimate of the magnitudes of capillary forces acting within a damp paper sheets, as it is being dried, can be obtained by imagining two smooth ribbon-like fibers of the same size that cross each other at a right angle. Now assume that there is a droplet of water positioned at the point of close contact, and that the water perfectly wets the fiber surfaces. In other words, one assumes a contact angle of zero degrees. In that case, Campbell (1959) showed that the negative pressure within the meniscus is given approximately by the following expression,

$$
\Delta P \approx \gamma / r \approx 2 \gamma / x
$$

where $\gamma$ is the water-vapor interfacial tension, $r$ is the smaller radius of curvature at the edge of the film of water, and $x$ is the distance of separation between the solids. This situation is illustrated in Fig. 2. Lyne and Gallay showed that capillary forces, including the type represented by Eq. (1), can result in a several-fold reduction of thickness of wet paper as water is removed from it. To paraphrase Ratliff (1949), one assumes that any parts of the adjacent fibers that are within the distances associated with optical contact will be drawn into molecular content during drying, as a result of the capillary forces.

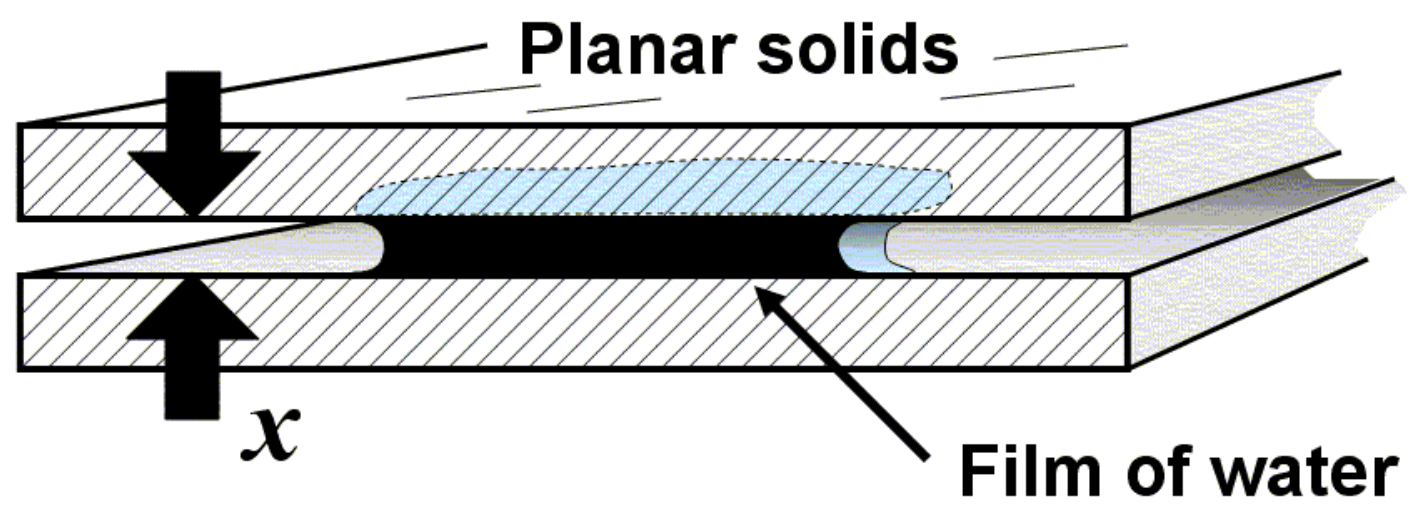

Fig. 2. Illustration of film of water between two flat, planar, perfectly-wetting surfaces, resulting in an attractive force proportional to the wetted area and inversely proportional to the separation distance

If one attempts, uncritically, to apply Eq. (1) to various situations, one quickly discovers that the negative pressure drawing two surfaces together is predicted to become infinite at zero separation. Since such a result is absurd, it is clear that the assumptions under which the equation was derived must cease to be accurate long before the last of

Hubbe. (2006). "Bonding between cellulosic fibers," BioResources 1(2), 281-318. 
the water has evaporated. Nevertheless, it has been predicted that negative pressures within capillaries can reach about 2 metric tons per $\mathrm{cm}^{2}$ during the drying of paper (Campbell 1959; Clark 1985a). Though these values are a factor of ten or more times lower than the pressures exerted within the nip of a wet press on a paper machine (Back 1987; Mather et al. 1987), the latter forces act only during the brief instant while the wet web of paper is passing through a nip. The capillary forces, on the other hand, can continue to act over longer periods of time. On this basis it is sometimes concluded that the capillary forces overcome the effects of roughness and force the fibers into molecular contact (Campbell 1959).

Some of the strongest evidence in support of the "drawing into molecular contact" theory just described consists of the dramatic decrease in fiber surface area when paper is dried (Davison 1980). The changes in kraft fiber properties associated with drying are generally attributed to partially irreversible closure of nanopores within the cell walls (Stone and Scallan 1966; Hubbe et al. 2003b), making the fibers less conformable and less able to swell with water (Nazhad and Pazner 1994). Capillary forces appear to be at least partly responsible for such effects.

Generally, it is not possible to discern spaces between fibrils at the surfaces of dried fibers, even by use of the most sensitive electron microscopic methods (Nanko et al. 1989; Nanko and Ohsawa 1989; Duchesne et al. 2003). Mayhood et al. (1962) observed nearly a constant strength of per unit area of apparent bonding between different kinds of papermaking fibers; on this basis they assumed that capillary forces are generally strong enough to overcome surface roughness and bring facing surfaces of fibers into molecular contact, regardless of the conditions of pulping and refining. Further evidence that molecular contact is achieved comes from the appearance of fiber surfaces after tensile failure. Areas that formerly were in optical contact generally show damage, such as raised and broken fibrils (Page 1960; Sachs and Kuster 1980; Clark 1985a; Nanko et al. 1989; Stratton and Colson 1993). Such damage was found to increase when a strength agent was used during formation of the paper (Stratton and Colson 1993). In many cases bonding between fibers is sufficiently strong, during the drying of paper, that lateral shrinkage of one fiber can cause lengthwise crimping of an adjacent fiber, resulting in an overall shrinkage of paper during unrestrained drying (Page and Tydeman 1962).

Though there would seem little reason to doubt the capillary mechanism of drystrength development, as just described, some of the experimental evidence in its favor is difficult to interpret. For instance, it has been shown that the presence of surface-active materials often results in weaker paper (Brandal and Lindheim 1966). In principle, surface-active materials are expected to decrease the value of $\gamma$ in Eq. (1), thus decreasing the capillary forces that draw surfaces together as paper is dried. However, there is a second explanation, which appears equally able to explain such results. That is, surfaceactive materials at fiber surfaces tend to block potential sites for hydrogen bonding (Brandal and Lindheim 1966). The latter mechanism is better able to account for the fact that cationic surface-active agents are much more harmful to paper's dry-strength, compared to anionic or nonionic surfactants, which have less tendency to adsorb onto anionic cellulosic surfaces (Touchette and Jenness 1960). Freeze-drying of paper, so that capillary forces are minimized, results in paper with no strength (Lyne and Gallay 1954); however such results also can be attributed to the non-conformability of frozen fibers. 


\section{Mutual Diffusion of Macromolecules at Facing Surfaces}

A second explanation to account for the development of molecular contact between the facing surfaces of two fibers is based on the thermodynamics of mixing (Robinson 1980; McKenzie 1984; Pelton 1993). Water is envisioned as a solvent for segments of macromolecules such as hemicellulose and microfibrils of cellulose, etc., that protrude from each fiber's surface (Clark 1985b). The idea is that the molecular segments already tend to mix with each other in the wet state, before the start of the drying process. A random process of molecular motions would be expected to result in interpenetration and tangling, i.e. a three-dimensional zone of contact (McKenzie 1984; Pelton 1993). As water is removed from such a swollen polymeric mass, the two surfaces become welded together. Consistent with this mechanism, it is generally found that inter-fiber bond strength increases as fibers become more highly swollen with water (Thode and Ingmanson 1959), either as a result of refining or chemical treatment.
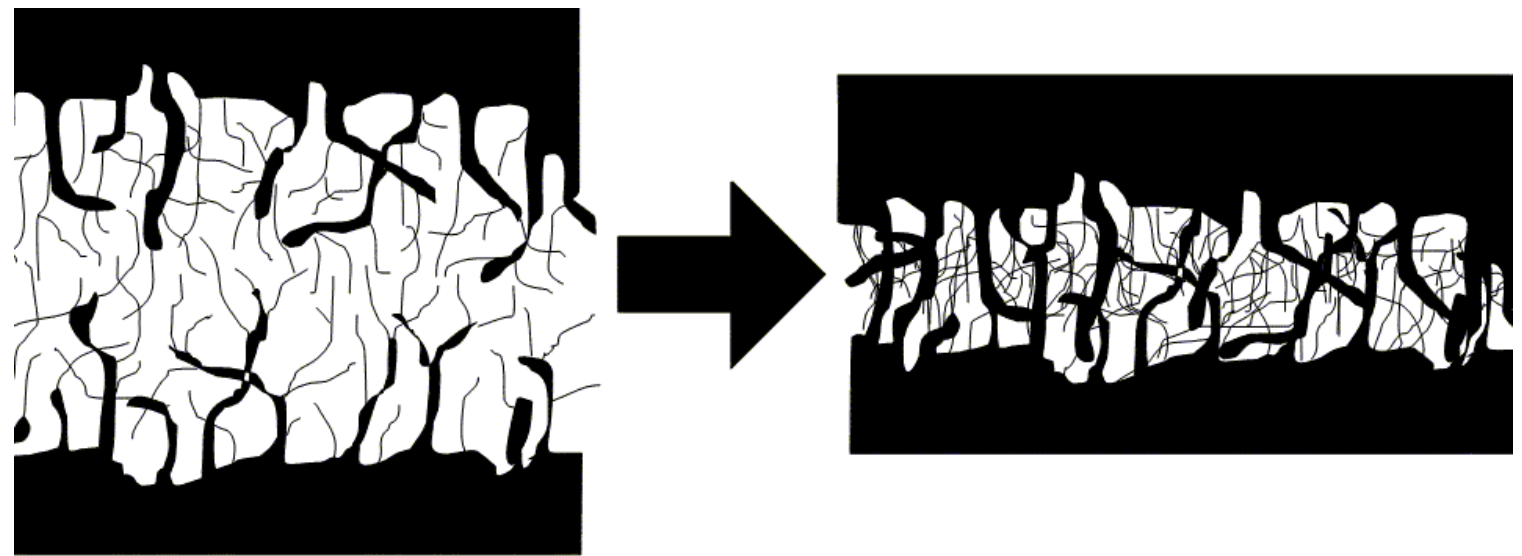

Fig. 3. Conceptual illustration suggesting that diffusional mixing of macromolecular segments extending from two wetted surfaces is likely to condense into a welded, 3-dimensional joint when the structure is dried

Cogent evidence supporting the inter-diffusion theory of bonding has been based on the principle that chemically different polymers do not tend to mix with one another, even if both are fully soluble in a surrounding liquid phase (Paul and Barlow 1982; Pelton et al. 2000). Such mixtures spontaneously remain as separate phases, each phase rich in one of the components. Pelton et al. (2000) tested such a mechanism by treating certain fibers with a water-loving cationic polyelectrolyte and other fibers with a polyelectrolyte having the same density of cationic charge, but a proportion of hydrophobic groups, such that the two polymer solutions did not mix. Highest strength was observed when fibers having the same surface treatment were dried. Lowest strength was obtained when incompatible fibers were blended together at an intermediate ratio. Earlier it had been shown that cellulose acetate and cellulose ether fibers, which are partly soluble in acetone, can be formed into very strong sheets, using acetone as a suspending medium (Bletzinger 1943). Ordinary cellulosic fibers, which are completely insoluble in acetone, did not develop any bonding when the paper was formed from acetone.

A different view of how cellulosic microfibrils behave during the drying of paper has been described by Nanko and Ohsawa (1989). Rather than observing a random 
process of macromolecular arrangement, as might be assumed based on the diffusional theory of bonding, these authors observed a lining up of microfibrils, flat against the adjacent fiber surfaces. Many microfibrils appeared to arrange themselves as bridges between the adjacent surfaces. Thus it appears that the inherent nature of cellulosic materials, tending to form fibrillar structures, creates a bias towards regularity of structures within bonded regions between fibrillated surfaces.

\section{Conformability}

Unless the surfaces of the fibers are conformable under the conditions present during drying, there is little hope of forming a strong sheet of paper (Clark 1973). This fact can be amply demonstrated by forming paper from glass microfibers (Lyne and Gallay 1954; Hubbe 2005). Such fibers resemble cellulosic fibers with respect to being fully wettable by water and forming a relatively uniform suspension in water, as long as the solids content is kept quite low. Though it is possible to form nice-looking paper test sheets from such fibers suspensions, in the absence of polymeric treatment the resulting dry-strength is close to zero. Blowing on the glass "paper" causes the fibers to come apart and rise up into the air (Hubbe 2005).

It is well known that cellulosic fibers become more conformable when they experience multiple compressions and shearing action, as they pass through a refiner in the presence of water (Baker 1985; Scallan and Tigerström 1992; Paavilainen 1993). There are two lines of thought as to how this happens. On the one hand, the repeated "impacts" of pinch points within a refiner are known to delaminate the fibers, both internally and on the surface. One can use the analogy of a rope, in which the filaments can slide past one another, to explain greater flexibility following delamination; by contrast, a board, in which the filaments are fused together, is much more rigid. The other main explanation for increased flexibility is that refining increases the swelling of fibers (Scallan and Tigerström 1992; Dulemba et al. 1999). In other words they hold more water. In certain cases it is possible to find strong correlations between fibers' swelling ability, as indicated by water retention during centrifugation, and the strength of the resulting paper (Ingmanson and Thode 1959). In other cases the correlation between strength and water retention can be weak (Jayme and Büttel 1968; Fält and Wågberg 2003), showing that swelling is not the only important factor.

The conformability of cellulosic fibers also can be changed by chemical modification. By oxidizing or derivatizing the fibers, creating a higher proportion of carboxylate groups at $\mathrm{pH}$ values greater than about 4, one can increase the degree of swelling (Roberts 1992). Fibers modified in this way have been found to yield stronger paper (Walecka 1956; Minor et al. 1991; Fors 2000). This mechanism helps to explain why paper formed under alkaline conditions tends to have a strength advantage relative to sheets formed from acidic media (Lindström and Kolman 1982).

It is not certain whether the strength benefits due to increased acidity of the fiber are a mainly a bulk phenomenon or a surface phenomenon. On the one hand, an overall higher negative charge of the fibers would be expected to increase their interaction with water (Grignon and Scallan 1980; Fors 2000) and also make fibrils extend outwards from the fiber surface (Clark 1985a; Pelton et al. 2000). On the other hand, derivatization reactions can be directed towards the outer surfaces of fibers, either by use of non- 
swelling solvents (Ehrnrooth et al. 1977) of by drying the fibers to close up pores and make the cell walls inaccessible to the reagent (Barzyk et al. 1997). By making the fiber surfaces more bondable, while leaving the interior of fibers in their original stiff, it is possible to achieve bulky, yet strong sheets of paper (Barzyk et al. 1997; Fors 2000).

Taking an opposite approach, acetylation at moderate to high levels tends to decrease the conformability of cellulosic fibers, when they are wetted by aqueous solution (McKenzie 1987). Thus, paper made from acetylated fibers tends to be bulkier and the strength can be reduced substantially (Nissan and Sternstein 1964). It would be easy to jump to the conclusion that even small degrees of acetylation would decrease the water-holding ability of cellulose or hemicellulose macromolecules at the fiber surface, thus interfering with the diffusional bonding mechanism described earlier. Tests of paper formed from slightly acetylated fibers showed, however, that the strength per unit of bonded area either remained constant or increased (Swanson 1956; McKenzie 1987). This effect can be attributed to the fact that low degrees of derivatization tend to disrupt the regularity of the macromolecules so that there tends to be less local crystallization. Greater mobility of the macromolecules at the fiber surfaces appears to enhance bonding.

There is a reasonable doubt that the preceding discussion of conformability makes sense in the case of mechanical pulp fibers, which are generally stiffer than kraft fibers. However, mechanical pulps tend to have relatively high levels of fiber fines. Moss and Retulainen (1997) showed that fines play a key role in the establishment of inter-fiber bonds in paper formed from thermomechanical pulp (TMP). Paper formed in the presence of fines was denser than paper formed from fractionated pulp with the fines removed (see also Seth 2003). Micrographs appeared to show tethers of fibrils from a layer of fines connected to each of two facing fibers. Such tethers tended to contract upon drying, drawing the fibers in the sheet closer to each other. It appeared that the presence of fines in the junctions between fibers helped to stabilize bonds, keeping the bonded areas from jumping apart after the paper became dry. Nanko et al. (1989) reported related observations of colloidal material efficiently filling up the space within bonded regions between fibers in dried paper. More recently, Lindström et al. (2006) proposed that dry-strength agents may help stabilize aqueous menisci as paper is dried.

\section{Hydrogen and Other Non-Covalent Bonds}

Due to the hydrophilic nature of fiber surfaces, it is to be expected that hydrogen bonds, in addition to London-van der Waals (dispersion) attractions, will hold the fibers together after paper is dried (Pierce 1930; Campbell 1947, 1959; Page 1969; Davison 1980; Fowkes 1983). The strong dependence of paper strength on relative humidity (Page 1969), as well as the ease with which paper can be recycled by addition to water, testify to hydrogen bonds' central importance. To keep things in perspective, however, there are many other kinds of materials that are quite strong even though they are unable to form hydrogen bonds. Polypropylene is a good example. The macromolecular chains within a polypropylene bottle are held together mainly by dispersion forces.

In the case of cellulose, individual macromolecules appear to have both internally and externally directed hydrogen bonds (Mann and Marrinan 1958; Gardner and Blackwell 1974; Kadla and Gilbert 2000). The latter, in principle, can contribute to bonding of hydroxyl groups on one macromolecular segment with adjacent chains in a 
fiber or with other materials at the fiber surface. The formation of hydrogen bonds between cellulosic surfaces appears to be involved in the partial irreversibility of pore closure in the cell walls when kraft fibers are dried (Stone and Scallan 1966). Corte and Schaschek (1955) estimated that only about 0.5 to $2 \%$ of $\mathrm{OH}$ groups present at the fiber surfaces are involved in inter-fiber bonding. This observation is worth keeping in mind for later in this article, when different papermaking additives are considered. One might expect, correctly, that additives capable of forming hydrogen bonds would tend to be the most successful dry-strength agents. As described by Robinson (1980), the presence of highly flexibility, water-loving macromolecules, such as hemicellulose, makes it possible for a higher proportion of hydroxyl groups at the fiber surfaces in the zone of contact to take part in adhesion.

\section{Interfiber Bonds as the Weak Link}

Paper's ability to resist tensile failure can be modeled by considering the strengths of individual fibers and the bonds between those fibers (Helle 1965; Page 1969). For kraft fibers, reasonable success has been achieved by applying a concept of relative bonded area, $R B A$, a quantity that is based on light scattering experiments (Parsons 1942; Ingmanson and Thode 1959; Page 1969). To carry out this analysis, one assumes that the scattering of light, as it passes through paper, is directly proportional to the fiber surface area in contact with air. Bonded areas do not contribute to light scattering, since the light can pass from one fiber to the next with no change in refractive index.

To determine the value of $R B A$ in a given case, the light scattering coefficient of a paper sample of interest is compared relative to a sheet of similar composition that is formed from a non-swelling solvent, such as butanol (Parsons 1942). Because the cellulosic fibers cannot conform to each other, when paper is prepared using the non-swelling solvent, the resulting sheets are extremely weak. To a reasonably good approximation, one can assume that each fiber's surface is surrounded by air, giving close to the maximum number of changes in refractive index as light passes through the non-bonded "paper." The relative bonded area is then defined as follows,

$$
R B A=\left[s_{\text {non-bonded }}-s_{\text {test sample }}\right] / s_{\text {non-bonded }},
$$

where $s_{\text {non-bonded }}$ is the scattering coefficient of the paper sheet formed from butanol, and $S_{\text {test sample }}$ is the scattering coefficient of the test sample, which is assumed to have an identical composition. In the case of kraft pulps it has been shown that paper's tensile strength can be approximately modeled according to the following equation (Page 1969),

$$
1 / T=9 /(8 Z)+12 A \rho g /[b P L(R B A)]
$$

where $T$ is the maximum tensile force before failure, usually expressed as a breaking length, $Z$ is the zero-span breaking length, giving an indication of fiber strength, $A$ is the average fiber cross-sectional area, $\rho$ is the density of the fiber material, $g$ is gravitational acceleration, $b$ is the shear bond strength, $P$ is the perimeter of a fiber, $L$ is the length of a fiber, and $R B A$ is the relative bonded area, expressed as a fraction. In more recent work 
the value of $R B A$ has been calculated based on procedures that do not require preparation of a non-bonded sheet (Görres et al. 1995; Batchelor and He 2005).

The first term in Eq. (3) involves breakage of individual fibers, whereas the second term involves separation of inter-fiber bonds. In many cases of practical interest it can be shown that bond strength tends to be the limiting factor (Page 1969; Robinson 1980). Thus, despite the various potential contributions to bonding strength, as outlined in the previous subsections, there is still plenty of motivation for papermakers to increase the strength or toughness of bonded regions, by addition of chemical agents. The latter help paper withstand various types of stresses and strains. Görres et al. (1995) found that the shear bond strength $b$ was higher in the case of kraft fibers, in comparison to mechanically refined fibers, a result which is consistent with the less hydrophilic nature of lignin and the debonding effect of extractives present in the high-yield pulps.

\section{POLYMERIC ENHANCEMENT OF INTER-FIBER BONDING}

Two concepts continue to be important when water-soluble polymer additives are used to enhance Interfiber bonding, beyond what can be achieved by forming paper from the untreated fibers. The first concept, as already noted, is that there is reason to believe that inter-fiber contact is likely to be inefficient, especially if papermakers are under constraints that limit the degree of refining of the fibers. The second notion is that events taking place on a scale of nanometers during drying are likely to play a huge role in the development of paper strength, with or without polymeric additives.

\section{Individual Polyelectrolytes}

Substantial gains in paper's strength properties are often observed following addition of individual polyelectrolytes to the fiber slurry (Reynolds and Wasser 1980; Hofreiter 1981; Bhardwaj et al. 1997; Ketola and Andersson 1999; Linhart 2005; Lindström et al. 2005). Commonly used dry-strength additives include derivatives of biopolymers such as starch, guar gum (Leech 1954; Dugal and Swanson 1972), and carboxymethylcellulose (CMC) (Horsey 1947; Beghello et al. 1997; Zhang et al. 2002; Hubbe et al. 2003a; Ekevåg et al. 2004; Watanabe et al. 2004; Lofton et al. 2005). Among these, cationic starch is by far the most widely used (Moeller 1966; Harvey et al. 1973; Marton and Marton 1976; Greif and Gaspar 1980; Hofreiter 1981; Lindström and Florén 1984; Roberts et al. 1986; Howard and Jowsey 1989; Alince et al. 1990; Formento et al. 1994; Beaudoin et al. 1995). Copolymers of acrylamide are also widely used as dry-strength agents (Reynolds and Wasser 1980; Farley 1987; Spence 1999). Additives that perform effectively for strength enhancement tend to share some common features. These include a water-loving nature, a mechanism by which the material is retained efficiently at fiber surfaces, sufficiently high molecular mass so that the additive remains on the outer surfaces of the fibers, and an ability to form hydrogen bonds (Davison 1980; Farley 1987; Reynolds and Wasser 1980; Robinson 1980; Tiberg et al. 2001). The hemicellulose component of fibers shares many of these same attributes, so it is not surprising that addition of hemicellulose products to papermaking furnish tends to increase the strength (Obermanns 1936; Mobarak et al. 1973; Laine et al. 1997). 
As a general rule, increasing amounts of adsorbed dry-strength polymer are expected to yield increasing strength benefits (Roberts et al. 1986). Efficient retention on the fiber surfaces usually is achieved by charge interactions (Fleer et al. 1993; Wågberg 2000). For example, retention of cationic starch at the wet end of a paper machine is substantially more efficient, in comparison to uncharged, native starch (Roberts et al. 1987). Best results usually can be achieved if the polymer has only a relatively low substitution with cationic groups (Harvey et al. 1979; Park and Tanaka 1998; Wågberg 2000). Exceptions to this rule are observed at high concentrations of electrolytes or when the fibrous slurry contains high levels of anionic colloids. At conductivity levels above about $2000 \mu \mathrm{S} / \mathrm{cm}$ it can be an advantage to use relatively high-charge density cationic dry strength products (Glittenberg et al. 1994; Beaudoin et al. 1995; Bobacka et al. 1998; Malton et al. 1998). In the case of wet-end starch products, levels of nitrogen between about 0.2 and $0.33 \%$, i.e. between about $2.4 \%$ and $4 \%$ degree of substitution, are most common (Harvey 1979; Hofreiter 1981). Cationic acrylamide copolymers intended for use as dry-strength agents can have up to about $10 \%$ of cationic groups. As is depicted in Fig. 4, higher levels of cationic charge tend to reduce the amount of adsorbed additive (Durand-Piana et al. 1987; Zhang et al. 2000; Wågberg 2000). This effect has been attributed to two factors. First, higher positive charge provides a higher driving force for the polymer to lie down flat on the negative fiber surface. A flat adsorbed conformation is more efficient for the covering of a surface, relative to a three-dimensional conformation. Second, the charge on the adsorbing species can overwhelm the initial negative charge of the fiber surface, leading to a build-up of excess positive surface charge. Higher-charged cationic starches can maintain their dry-strength performance with increasing salt concentrations of the aqueous suspension (Beaudoin et al. 1995), but there is greater likelihood of overcharging the system.
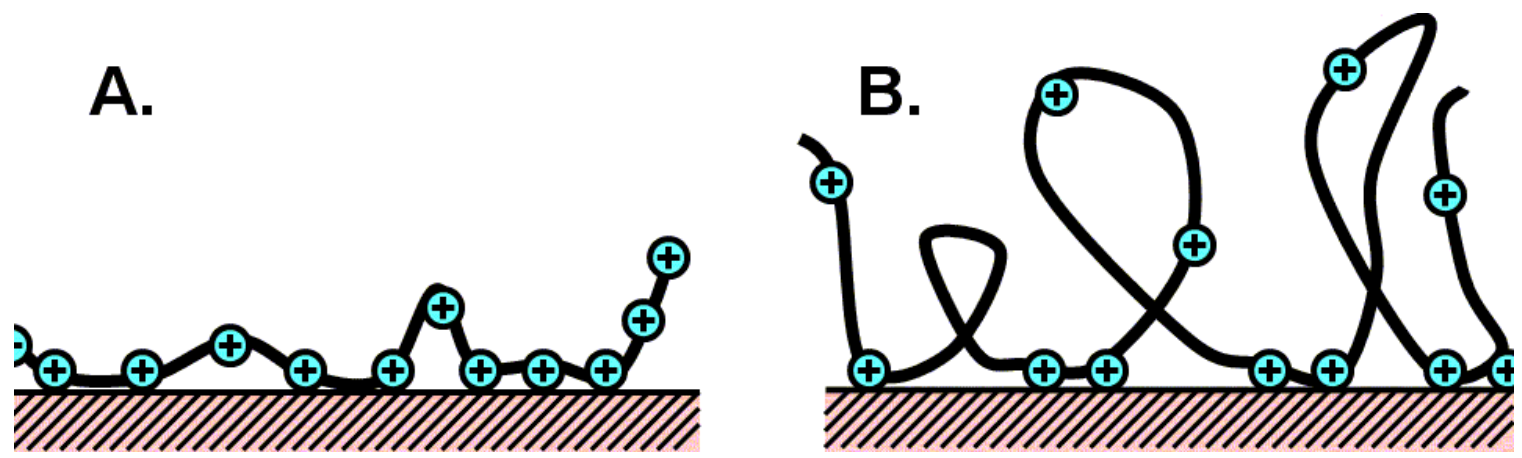

Fig. 4. Schematic illustration suggesting a greater degree of molecular extension from a surface in the case of a relatively low-charge cationic polyelectrolyte adsorbing onto a negatively charged substrate

The efficiency of cationic starch as a dry-strength agent usually is highest at addition rates up to about $1 \%$ on product mass (Roberts et al. 1986; Formento et al. 1994), or somewhat higher if the furnish contains relatively high amounts of filler and well-refined fibers, offering a relatively high surface area (McKenzie 1964). Beyond about $2 \%$ addition, one can expect that increasing proportions of the added cationic starch will remain in the solution phase rather than becoming adsorbed. As shown by Marton (1980), the available surface area is likely to become the limiting factor. 
There does not appear to be a simple relationship between molecular mass and strength benefits (Hofreiter 1981; Zhang et al. 2001). In the case of acrylamide copolymers, some research has suggested an optimum molecular mass of about 100,000 to 500,000 grams per mole (Reynolds and Wasser 1980). Other work has suggested increasing effectiveness with increasing molecular mass (Carlsson et al. 1977; Pelton et al. 2003). Linear acrylamide copolymers of very high molecular mass tend to act as flocculants, hurting the uniformity and strength of the resulting paper. By contrast, the molecular mass of amylopectin molecules in commonly used starch products has been estimated to be in the range of hundreds of millions of grams per mole (Whistler et al. 1978; Swinkles 1985; Olsson et al. 2003; Modig et al. 2006). Higher dry-strength performance is sometimes reported for starch products that are rich in amylopectin (Beaudoin et al. 1995). The important distinction appears to be that the amylopectin molecules are highly branched, giving them a more compact conformation in solution and a reduced tendency to flocculate fibers.

The relative ineffectiveness of various low-mass analogues of dry-strength polymers provides an important clue as to how these materials function. By means of electrokinetic tests such as microelectrophoresis (Strazdins 1977; Koethe and Scott 1993; Farley 1997) and streaming potential tests (Penniman 1992; Koethe and Scott 1993; Wang and Hubbe 2002) it can be shown that cationic polyelectrolytes of decreasing molecular mass tend to penetrate more rapidly beneath the outer surfaces of kraft fibers. In addition, the amount of dry-strength resin adsorbed onto fibers often increases with increasing time of mixing (Abson and Brooks 1985). Though other explanations are possible, it appears that time may permit strength resins to migrate into hidden positions, either within the cell wall or within layers of fibrils at the fiber surfaces (Zhang et al. 2001). Such results can help to explain a decreased effectiveness of various strength resins with increasing time of exposure to the fiber slurry (Spence 1999).

As noted in a recent review (Hubbe et al. 2006a), it is not certain whether most of this migration of polyelectrolytes into fibers involves the $2-100 \mathrm{~nm}$ pore spaces within the cell walls themselves, or just spaces within layers of fibrils at the fiber surfaces. Adsorption experiments with silica gel, having well-defined pore size, have shown relatively little penetration of high-charge, linear polymer into $15 \mathrm{~nm}$ pores over time scales of several minutes (Hostetler and Swanson 1974; Hubbe et al. 2006b). Results of the more recent studies involving bleached kraft fibers (Hubbe et al. 2006a) suggest that the interior spaces within cell wall pores remain mostly uncovered by cationic polymers within the time periods usually associated with papermaking operations. Likewise, Tatsumi and Yamauchi (1997) observed only limited migration of cationic polymers into kraft fibers.

Gupta and Scott (1995) observed the most efficient contributions of cationic starch products to strength in cases exhibiting a strong decay of streaming potential with time. Such observations are consistent with non-equilibrium adsorbed conformations. In principle, a macromolecule that has not yet reached an energetically favorable adsorbed conformation would be expected to have a greater capability of associating with a second surface during the formation and drying of paper.

Effects of molecular mass hold the potential to shed light on the mechanism of bonding. In principle, a larger molecule, having a larger effective size in solution, would be expected to be more effective in filling void spaces, in areas where the facing surfaces 
of rough materials are otherwise unable to make contact on a molecular case. Such "space-filling" mechanisms, to account for the action of dry-strength additives, have been proposed (Tiberg et al. 2001). Howard and Jowsey (1989) carried out critical experiments to address this question in the case of cationic starch. Independent variables in their study included whether or not cationic starch was added to the fiber suspension and the pressure applied to the sheets before they were dried. Increasing wet-pressing increased paper strength and decreased opacity, consistent with an increase in $R B A$, as was defined in eq. (2). Relative to the baseline, addition of starch increased the paper's tensile strength with only a minor decrease in opacity. The authors concluded that cationic starch mainly increased the bond strength per unit of bonded area. Related results were reported by others (Reynolds and Wasser 1980; Gaspar 1982; Retulainen and Nurminen 1993; Zhang et al. 2001; Yamauchi and Hatanaka 2002), some of whom observed significant increases in $R B A$ with increasing cationic starch addition (Formento et al. 1994). Hofreiter (1981) suggested that water-loving polymers, such as cationic starch, can tend to draw paper together into a denser structure as paper is dried.

When interpreting results of the type just described, it is important to recognize that eq. (2), which defined the meaning of $R B A$, is based on optical measurements. Such measurements are relatively insensitive to the presence of air gaps thinner than about 200 nm. If cationic starch acts by "filling in void spaces," its effects must be associated with gaps much narrower than a wavelength of light. As noted by Pelton (2004), when one considers the amounts of various dry-strength additives that adsorb onto papermaking materials, one would expect the dried polymer layers to be about $1 \mathrm{~nm}$ thick.

As noted earlier in this issue of BioResources (Green 2006), paper's strength is affected by stresses within the plane of the sheet as it is being dried. Though details of this subject lie beyond the scope of this review, a study by Vainio et al. (2006) has revealed a connection between drying stresses and dry-strength additives. The authors observed, in general, that drying stresses tended to decrease the density of inter-fiber bonding, even in cases where the in-plane tensile strength was improved. However, it appeared that optimum dry-strength chemicals or polyelectrolyte complexes (see later) were able to counteract the negative effect of drying stress on bond strength, yielding an overall improvement in paper strength properties. The authors suggested that the drystrength polymers can provide a flexible layer at the junction between fibers.

\section{Anionic Polyelectrolytes}

When attempting to achieve higher strength gains than could be achieved by starch products, one of the first kinds of wet-end additives considered by papermakers has been anionic copolymers of acrylamide (Chan 1976). To retain such polymers efficiently onto cellulosic fibers, which are tend to be anionic, it is necessary to add something cationic to the system. During the 1960s and 1970s, when most printing papers in the US were manufactured under acidic $\mathrm{pH}$ conditions, aluminum sulfate (papermaker's alum) was commonly used in such a role. The effectiveness of alum, in combination with anionic acrylamide copolymers, tended to be maximized at $\mathrm{pH}$ values between 4.2 and 4.5 (Reynolds 1961; Linke 1968; Reynolds 1980; Reynolds and Wasser 1980). Such a maximum, versus $\mathrm{pH}$, is consistent with the expected formation of highly cationic oligomeric aluminum species that becomes prevalent within that range of $\mathrm{pH}$, 
depending on such factors as concentration, time, temperature, and the concentration of sulfate ions (Akitt et al. 1972; Bottero and Fiessinger 1989; Crawford and Flood 1989; Strazdins 1989). Results also suggest that best strength results are achieved when the amount of aluminum ions is sufficient to neutralize the negative charge of the polymer. The same mechanism appears to account for the effectiveness of certain anionic derivatives of natural products. These include carboxymethylcellulose (CMC), added sequentially with alum under acidic papermaking conditions (Horsey 1947). Anionic starches also show promise, when added sequentially with cationic polymers (Schneider and Huang 1993; Brouwer 1997; Wielema and Brouwer 2003).

To be fair, the explanation just given is not the only credible explanation of the cited results. For instance, one can suppose that the cationic materials in the system adsorb onto solids surfaces and they then can act as anchoring points for the anionic polyelectrolytes. Evidence for this anchoring mechanism was found in a study in which the dosages were carefully controlled, allowing a highly cationic polymer to become adsorbed almost quantitatively, prior to the addition of an anionic dry-strength polyelectrolyte (Hubbe et al. 2003a). Under certain conditions, the contribution of anionic $\mathrm{CMC}$ to the compression strength of linerboard could be maximized if the fiber surfaces had been exposed to just enough cationic polymer to saturate their adsorption capacity. Not only did those conditions achieve the highest compression strength of the paper made from never-dried unbleached kraft fibers, but the advantage continued to be clearly evident when the same fibers were reslurried and formed into recycled paper.

Recently a contrary approach has been advocated in which fibers are treated with anionic carboxymethylcellulose (CMC) in the absence of cationic additives. Even though CMC has a negative charge, enough of it appears to adsorb onto fiber surfaces so that substantial dry-strength gains can be achieved (Beghello et al. 1997). In addition to acting as a bonding agent, it seems likely that the adsorbed CMC acts as a kind of lubricant on the fiber surfaces (Mason 1950; Swanson 1950; Leech 1954; Zauscher and Klingenberg 2000), thereby reducing the flocculation tendency. More uniform paper is expected to be stronger (Linhart et al. 1987; Nazhad et al. 2000). More recently it was found that higher levels of CMC can be attached to fiber surfaces by prolonged heating under pressure at $120{ }^{\circ} \mathrm{C}$ in the presence of $0.05 \mathrm{M}$ calcium chloride (see Fors 2000). It appears that $\mathrm{CMC}$ is able to hydrogen bond efficiently to the cellulosic surfaces due to chemical similarity, and that such bonding is difficult to reverse completely.

Regardless of how the anionic polyelectrolyte is made to adsorb onto fiber surfaces, it is possible to draw an analogy to the fiber surface derivatization (Walecka 1956; Marton and Marton 1976; Wågberg et a. 1989; Minor et al. 1991; Roberts 1992; Fors 2000) and fiber surface oxidation work (Alince 1975; Saito and Isogai 2005), some of which was cited earlier. Recall that certain such treatments, on their own, had a very positive effect on the dry strength of the resulting paper, even without the addition of polyelectrolytes (Walecka 1956; Minor et al. 1991; Fors 2000). Contributing mechanisms, to explain those effects, included a greater swelling of the cellulosic material, i.e. a greater tendency to hold onto water. Treatment of fiber surfaces with anionic polyelectrolytes can be viewed as an alternative way to increase the water-holding ability of the fiber surfaces. The anionic charges are expected to induce an osmotic effect, causing water to swell the polymeric material. Seen in another way, repulsion between the ionic 
double-layers surrounding the negatively charged polymer chains is expected to make them extend outwards from the fiber surface, enabling more efficient interdiffusion of macromolecules at the fiber surfaces. One of the problems, though, is that papermakers sometimes have to "use up" some of the negative polymer charge by addition of cationic materials in order to achieve efficient fine particle retention.

\section{Polyelectrolyte Complexes Formed In-Situ}

When solutions of oppositely charged polyelectrolytes are mixed, the resulting complexes can display a wide range of properties, including decreased solubility or an increased tendency to adsorb (Kötz 1993; Kekkonen et al. 2001; Mende et al. 2002; Gernandt et al. 2003). The charge and colloidal stability of polyelectrolyte complexes (PECs) can be controlled by adjusting the ratio of the two polymers (Gernandt et al. 2003). Results also can depend on salt concentration and mixing conditions. Substantial gains in dry strength can be achieved by addition of such pre-formed PECs to papermaking furnish (Heath et al. 1974; Nagata 1991; Gärdlund et al. 2003; Koljonen et al. 2003; Wu et al. 2004; Gärdlund et al. 2005). For example, it was found that combinations of cationic and anionic acrylamide copolymers were especially effective in increasing paper's dry-strength (Koljonen et al. 2003).

Several studies have shown evidence of paper strength increases due to in-situ formation and deposition of polyelectrolyte complexes within a fiber suspension (Carr et al. 1974, 1977; Smith 1992; Maximova et al. 2005). Related effects were observed during some recent work in which oppositely charged polyelectrolytes were added sequentially (Hubbe et al. 2003a). The working hypothesis was that the most promising gains in dry strength would be achieved if the fibers were treated first with just enough highly cationic polymer to saturate the fibers' adsorption capacity. Unexpectedly, however, even greater tensile strength of handsheets formed form repulped copy paper was observed if the first additive was greatly in excess of the saturation level. To explain the results, it was proposed that the excess of cationic polyelectrolyte in solution formed complexes with the subsequently added anionic polymer, and that the complexes adsorbed onto the fibers, contributing to dry strength (Hubbe et al. 2003a). The concept is illustrated in Fig. 5.

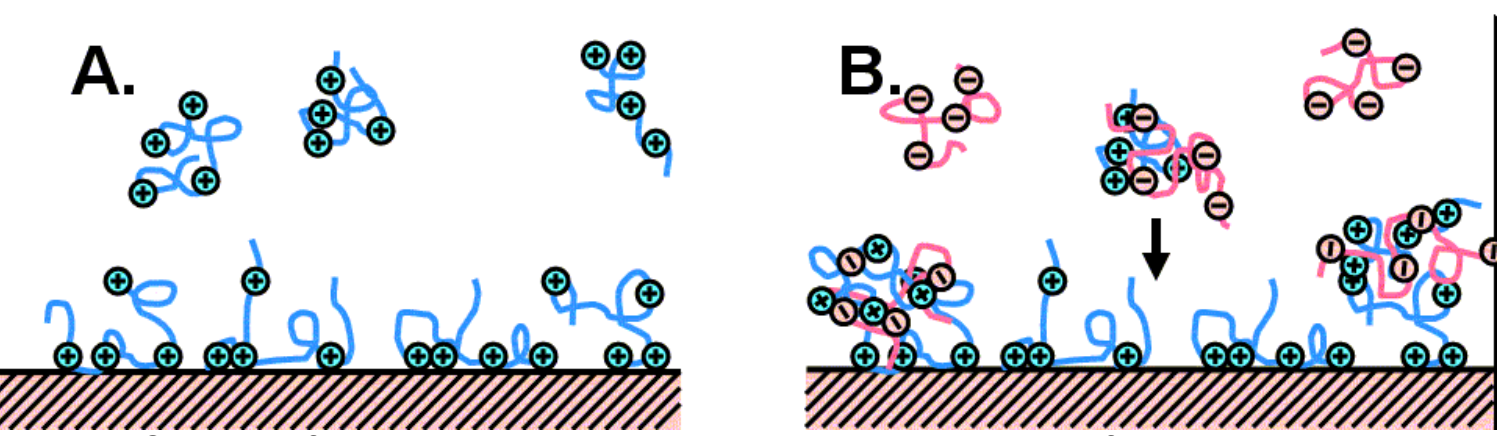

Fig. 5. Concept of a two-step treatment, starting with an excess of cationic polyelectrolyte, followed by anionic polyelectrolyte, creating polyelectrolyte complexes in the bulk phase, which subsequently deposit onto fiber surfaces, where they can contribute to paper strength 
This mechanism was corroborated in subsequent work, based on a tendency of polyelectrolyte complexes to increase the light scattering of an aqueous suspension (Lofton et al. 2005; Hubbe et al. 2005; Hubbe 2005). The most promising results were obtained when the charge ratio of acidic and basic groups on the polyelectrolytes were within about a $2 / 3$ to $3 / 2$ ratio of each other (Hubbe et al. 2005; Hubbe 2005). Earlier work involving sequential addition of oppositely charged polyelectrolytes likewise showed that dry strength derived by this type of mechanism tends to be maximized when the ionic charges are approximately equal (Carr et al. 1977).

The manner in which polyelectrolytes are added to a fiber slurry can be critically important when one is attempting to increase strength by deposition of polyelectrolyte complexes. For instance, by pre-treating the fibers to make them cationic it was possible to shift the ratio of PEC charges corresponding to maximum retention of the polyelectrolyte complexes (Hubbe et al. 2005). PECs having a net negative charge were retained more effectively on the cationically pretreated fibers, yielding more efficient strength development. Follow-up tests with non-bonding glass fibers showed that sequential addition of the polyelectrolytes gave far superior results, compared to premixing the polyelectrolytes just before their addition to the fiber furnish (Hubbe 2005). A further decrease in strength contribution of the PECs was observed if there was a time delay before adding the polymer mixture to the fiber furnish. It appears that in-situ formation of PECs, in the presence of fibers, is able to take advantage of some non-equilibrium structures, which are somehow able to interact with fibers in a beneficial way before they become deactivated. A deactivation mechanism is consistent with an expected reconformation within freshly-formed PECs (Hubbe 2005).

A notable feature of PEC deposition, as a mechanism of dry-strength development, is the fact that the resulting paper strength continues to rise as the net polymer dosage increases to high levels. Thus, it was possible to form stiff, paper-like sheets from glass fibers (Hubbe 2005), skipping the mat impregnation step that is often used industrially for products made from non-bonding fibers (Williamson 1993). In one set of tests, strength increases continued to be very significant up to a level of about $40 \%$ dry weight of polyelectrolytes on kraft fibers (Heerman et al. 2006), above which point the fibers were so sticky that it was difficult to form laboratory sheets. In such cases it appears that strength is limited mainly by the high expense required to add so much polyelectrolyte and by the increased likelihood of sticky deposits.

Having demonstrated the mechanism, it is possible to cite other reported findings that appear to involve in-situ formation of PECs and their deposition onto fiber surfaces (Chan 1976; Lindström and Florén 1984; Nealey et al. 1989; Retulainen and Nurminen 1993; Schneider and Huang 1993; Zhang et al. 2002; Maximova et al. 2005). For instance, by sequential addition of anionic starch and polyaluminum chloride (PAC) it was possible to achieve paper strength gains usually associated with use of a size press (Brouwer 1997). A similar explanation might also account for the ability of polyvinylamine products to retain potato starch, which naturally has anionic phosphate groups (Lorenčak et al. 2000). In support of this mechanism, polyvinylamine was not effective for retaining unmodified tapioca starch, which lacks any anionic phosphate groups on its surface. Whereas conventional addition of cationic starch is limited to about 1 to $1.5 \%$ based on dry mass of fiber (Brouwer 1997; Glittenberg et al. 2004), it was possible to use 
as much as $6 \%$ anionic starch, added in sequence with PAC (Brouwer 1997). A recent study showed that paper strength can be increased by in-situ formation of complexes with wood-derived colloidal materials, which are subsequently retained in the paper (Maximova et al. 2005).

\section{Polyampholytes}

Based on chemical similarity, one might guess that some of the advantages obtained by the use of PECs, as just described, might be achieved more reliably and simply by using single polymers having both positive and negative ionic groups. Thus, the papermaker would need to handle just one additive, not two. Concerns about controlling the charge ratio and mixing procedures could be avoided in the paper mill. In particular, because the additive can contain a defined ratio of both positive and negative ionic groups, there is much less concern that the system becomes over-charged with positive or negative species (McQueary 1990; Dalidowicz 2000). In principle, an overdose of the system with a single-charged polymer can lead problems such as slow dewatering or inefficient retention of fine particles (Horn and Melzer 1975; Lindström and Söremark 1975; Goossens and Luner 1976; Strazdins 1994).

Evidence suggesting superior performance of amphoteric polymers in the role of dry-strength additives has been shown in a number of recent studies. For instance, a study by Yoshizawa et. al. (1998) showed that starch products prepared with both positive and negative ionic groups sometimes adsorb more efficiently on cellulosic fibers, in comparison with conventional cationic starches. Other studies have demonstrated increased rates of dewatering (McQueary 1990), and superior dry strength (McQueary 1990; Glittenberg 1993; Ghosh 1994) when using amphoteric starches. Related promising results also have been reported in the case of synthetic polyampholytes, based on acrylamide chemistry (Ye et al. 1990; Fukunaga 1999; Yoshimoto et al. 2004).

A series of studies was undertaken recently at North Carolina State University in order to better understand how polyampholyte composition and structure affect its behavior in aqueous solution, its adsorption characteristics, and its performance as a drystrength additive. Polyampholytes were prepared by random, free-radical polymerization with differing charge ratio (Sezaki et al. 2006a) and with differing density of charged groups at a fixed charge ratio (Wang et al. 2006a). The results of potentiometric titrations, sensing the dissociation of acidic and basic groups as a function of $\mathrm{pH}$, were found to be consistent with molecular compositions, as confirmed by NMR analysis.

Electrokinetic tests were used to characterize the polyampholytes. The electrophoretic mobility, as determined when the polyampholytes adsorbed onto microcrystalline cellulose indicator particles, depended strongly on $\mathrm{pH}$, even near the apparent isoelectric point in each case (Sezaki et al. 2006a). By contrast, the results of polyelectrolyte titrations, using a streaming potential endpoint, showed relatively little interaction of the polyampholytes with strongly charged polyelectrolytes over a wide range of $\mathrm{pH}$, especially in cases where the proportions of positive and negative charged groups were not too different (Sezaki et al. 2006a; Wang et al. 2006a). Streaming potential tests showed that polyampholyte-treated bleached kraft fibers or microcrystalline cellulose particles tended to be closer to neutral potential, compared to fibers treated with positive or negative polyelectrolytes of similar charge density (Wang et al. 2006a,b). 
Consistent with predictions of polyampholyte molecular conformations in aqueous solution, both the specific viscosity and the turbidity of polyampholyte solutions were found to be strongly dependent on pH (Sezaki et al. 2006a; Hubbe et al. 2006c; Song et al. 2006). Lowest viscosity and highest turbidity were observed in the neighborhood of the isoelectric point, where the quantities of positive and negative dissociated groups were approximately equal. These results were attributed to macromolecular contraction, due to association of oppositely charged groups. Addition of salt, sufficient to raise the conductivity to $1000 \mu \mathrm{S} / \mathrm{cm}$, resulted in a relative increase in viscosity and decrease in turbidity. Such observations provide examples of antipolyelectrolyte behavior (Lowe et al. 1999). The usual explanation is that the salt ions tend to screen interactions among the charged groups of the polyampholyte macromolecules, decreasing the tendency for molecular contraction under $\mathrm{pH}$ conditions at which the amounts of oppositely charged groups are similar.

Follow-up tests showed that polyampholyte adsorption onto bleached kraft fibers was maximized not far from the same $\mathrm{pH}$ values where bulk viscosity of polyampholyte solutions was at a minimum and turbidity was maximized (Sezaki et al. 2006b; Wang et al. 2006b). In principle, one can expect there to be ionic association between charged segments in adjacent polyampholyte molecules, leading to higher levels of adsorption (Glittenberg 1993). However, as has been found in another study of polyampholyte adsorption (Yoshizawa et al. 1998), the $\mathrm{pH}$ of maximum adsorption was shifted relative to the isoelectric $\mathrm{pH}$ in such a way that the net charge was weak, but opposite to that of the substrate. Except at $\mathrm{pH}$ values above 9, polyampholyte adsorption was found to be more efficient in comparison to adsorption of a polybase of similar charge density and molecular mass. Various kinetic effects were observed, suggesting that the polyampholytes are able to readjust their molecular conformations gradually after adsorption in response to the electrical field (Dobrynin et al. 1997; Wang et al. 2006b). This concept is illustrated in Fig. 6.
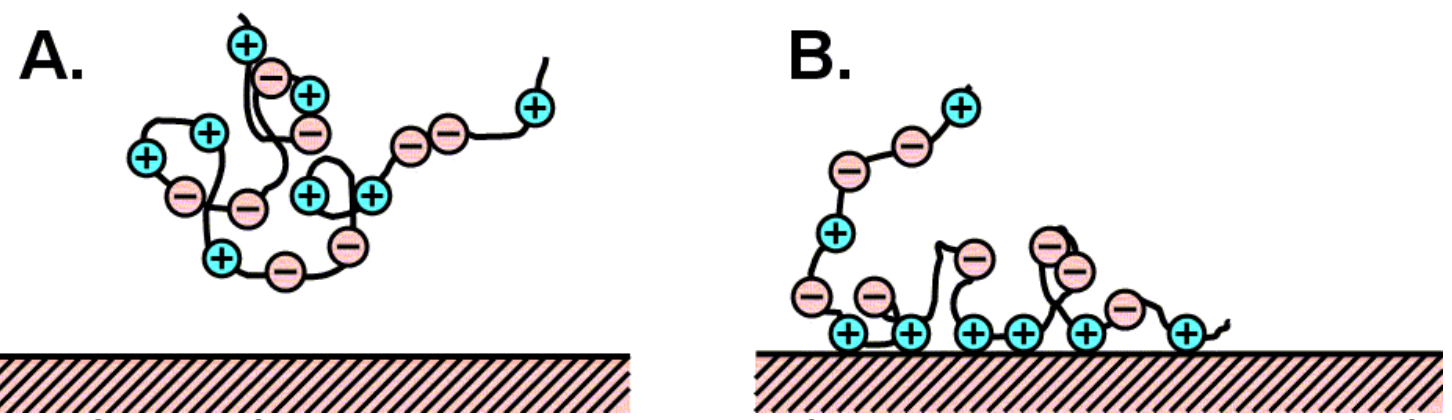

Fig. 6. Concept of macromolecular rearrangement of polyampholytes, making it possible for them to adsorb efficiently onto substrates having either sign of charge, assuming that the monomer charges are in moderate proportion with each other

Strength gains upon addition of polyampholytes to bleached kraft furnish were generally consistent with the results of the adsorption tests, and the polyampholytes were much more effective than ordinary polyelectrolytes of similar composition and mass (Hubbe et al. 2006c; Song et al. 2006). Effectiveness, in terms of dry strength, also increased with increasing density of ionizable groups. A further clue to the effectiveness 
of the polyampholytes, in addition to their more efficient retention on fibers, was obtained by centrifugation tests; the water retention of polyampholyte-treated fibers was significantly increased. No significant increases were observed when the fibers were treated with solutions of single cationic or anionic polyelectrolytes. These results agree with other studies, suggesting that water-swollen polymeric layers at fiber surfaces can yield higher bonding strength (Jayne et al. 1950; Carlsson et al. 1977; Fors 2000).

Further gains in dry-strength performance could be achieved by addition of polyaluminum chloride (PAC) before addition of polyampholytes to fiber suspensions (Song et al. 2006). The greatest relative boost in strength, due to PAC addition, was in the case of a polyampholyte having a relatively low level of charged groups, $2.5 \%$ base and $2 \%$ acid on a molecular substitution basis. The results appeared to be consistent with a complexation between positive aluminum ionic species and carboxylate groups on the polyampholytes, shifting the polymer change towards being more cationic.

While factors such as adsorption efficiency, a tendency to swell with water, and a tendency to achieve lower absolute values of streaming potential may be sufficient to account for the superior dry-strengthening effect of polyampholytes, under specified papermaking conditions, there might also be a contribution to bond strength arising due to ionic interactions. Unfortunately, there does not seem to be a completely satisfactory way to distinguish the contribution of ionic forces relative to other bonding contributions, such as London dispersion forces and hydrogen bonding. Also, the degree to which segments of a dry-strength polymer are charged can profoundly affect its ability to adsorb onto fibers, a key precondition of its effectiveness. Though some evidence has been presented in support of an ionic bonding mechanism (Reif 1972; Allan and Reif 1977; Allan et al. 1993), some of the results suggest that the contribution is not as important as other factors in terms of dry strength development (Akagane et al. 1979). Possibly the best evidence that ionic bonding plays a significant role in dry strength development comes from an early study of cationic starch (Moeller 1966). The strength gain due to the starch was approximately the same, regardless of whether the sheets were dried in the ordinary way or were freeze-dried. Since freeze-drying bypasses the effects of capillary forces, as well as the efficient development of hydrogen bonding, Moeller concluded that the bonding contribution of the starch must be mainly ionic.

\section{PROSPECTS FOR FUTURE DEVELOPMENTS}

\section{Preparing the Substrate}

In principle, additional anionic groups can be created on fiber surfaces and within the cell walls by oxidative bleaching, ozone, peroxide, or oxygen treatment (Barzyk et al. 1997). Carboxymethylation of fiber surfaces has shown advantages in both the ease of refining of kraft pulps and in the strength of paper made from those pulps (Walecka 1956; Minor et al. 1991; Fors 2000). In the vapor phase, negative charge can be induced by exposure to corona discharge (Goring and Suranyi 1969; Cramm and Bibee 1982; Clark 1985a) or to the vapors of maleic anhydride (Hubbe et al. 1999). A reaction between cellulosic or hemicellulosic hydroxyl groups with a halo-acetic acid compound will derivatize the cellulosic material with carboxymethyl groups (Barzyk et al. 1997). 
By carrying out such derivatization on recycled kraft fibers, which have experienced a drying cycle, the negative groups can be mainly limited to the outer surfaces (Fors 2000). Substantial strength gains were achieved, even tough the reagent could not penetrate into the fibers to change their bulk characteristics, such as conformability or swelling ability. Rather, the effects were attributed to increased bondability of the surface.

Marton and Marton (1976) were apparently the first to show that increasing the negative charged character of fibers could be used as a way to enhance their ability to adsorb cationic starch. The fibers were carboxymethylated to various degrees. The authors also demonstrated that cationic starch, once adsorbed onto fiber, could not be removed even by rinsing in hot water. Retulainen et al. (1993) showed that higher-yield fibers, having a higher density of negative charge, were able to adsorb cationic starch more efficiently compared to low-yield, bleached kraft fibers. Watanabe et al. (2004) showed that CMC-treated fibers achieved larger gains in strength upon subsequent addition of strength additives, in the presence of alum.

Figure 7 illustrates a possible way to implement fiber modification in a paper machine system, while adding a cationic polyelectrolyte. As shown, the pulp first is treated, by some means, to create a higher level of acidic groups on its surface. Next it is proposed that excess reagent ought to be washed from the pulp. Otherwise, excess chemical and byproducts might result in problems for the papermaker or end-user. Cationic dry-strength additives added after the washing stage, as indicated, would be expected to adsorb with high efficiency, leading to higher dry-strength performance.

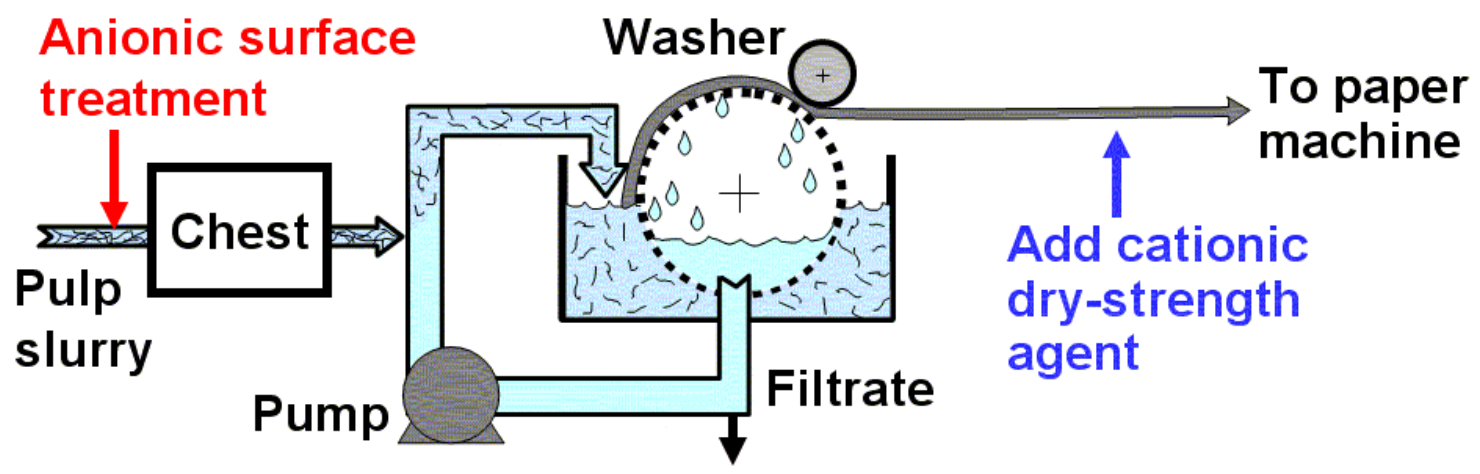

Fig. 7. Generalized concept of a two-step treatment, involving a surface derivatization, to make the fiber surfaces more negative, followed by treatment with positively charged dry-strength polymer

\section{Controlled Assembly}

The words "self-assembled" have become popular in recent studies that fall under the category of nanotechnology (Decher et al. 1992; Advincula et al. 1996; Decher 1997; Koetse et al. 2002). When they use this term, authors usually are referring to procedures by which individual macromolecules or colloidal particles align themselves in a regular order. In other words, the organization follows from the characteristics of the large molecules and the order of the mixing steps. The general principles of this approach recently were demonstrated in the case of papermaking materials (Wågberg et al. 2002). In the cited study self-assembled multi-layers (SAMs), composed of alternating layers of 
oppositely charged polyelectrolytes were deposited onto silicon wafers and onto cellulosic fibers. The total thickness of deposited macromolecules increased in regular steps during the self-assembly process. In a corresponding manner, the dry-strength of paper prepared from SAM-treated cellulosic fibers increased markedly with increasing numbers of deposited layers (Wågberg et al. 2002; Eriksson et al. 2005a,b). In certain cases the strength was strongly influenced by the nature of the final deposited layer (Wågberg et al. 2002; Eriksson et al. 2005a).

Despite the intriguing and seemingly promising nature of the results just cited, a key technological hurdle needs to be overcome before SAM technology can be considered to be a practical means of improving paper's dry strength. SAM procedures, in their current state of development, depend on alternating treatment of fibers with solutions containing excess amounts of polyelectrolyte, followed by rinsing steps (Hoogeveen et al. 1996; Decher 1997; Caruso et al. 1999; Dubas and Schlenoff 1999). The expense to install and run multiple sets of washing steps would tend to make SAM treatment economically unattractive. Fortunately, there is reason to be optimistic. An inherent problem with existing scientific studies of SAMs is that investigators tend to concentrate on forming alternating layers of supremely high regularity and purity. It has not been demonstrated that such ideality of alternating polyelectrolyte layers is truly important relative to the practical goals of increasing paper's strength.

Figure 8 illustrates a concept that can be likened to what happens when a chef goes on a camping trip with only one pot. Just as in a conventional papermaking operation, the chef can add ingredients to the pot, but nothing can be removed until the mixture is "ready." The main decisions to be made involve the order of addition and the amounts of materials that are added in each step. Occasionally the chef may taste a morsel. In principle, one would want to add just enough polyelectrolyte, in each alternating step, so that the fiber surface would become saturated, leaving no significant excess of that charge of polyelectrolyte in solution (Hubbe et al. 2003a).

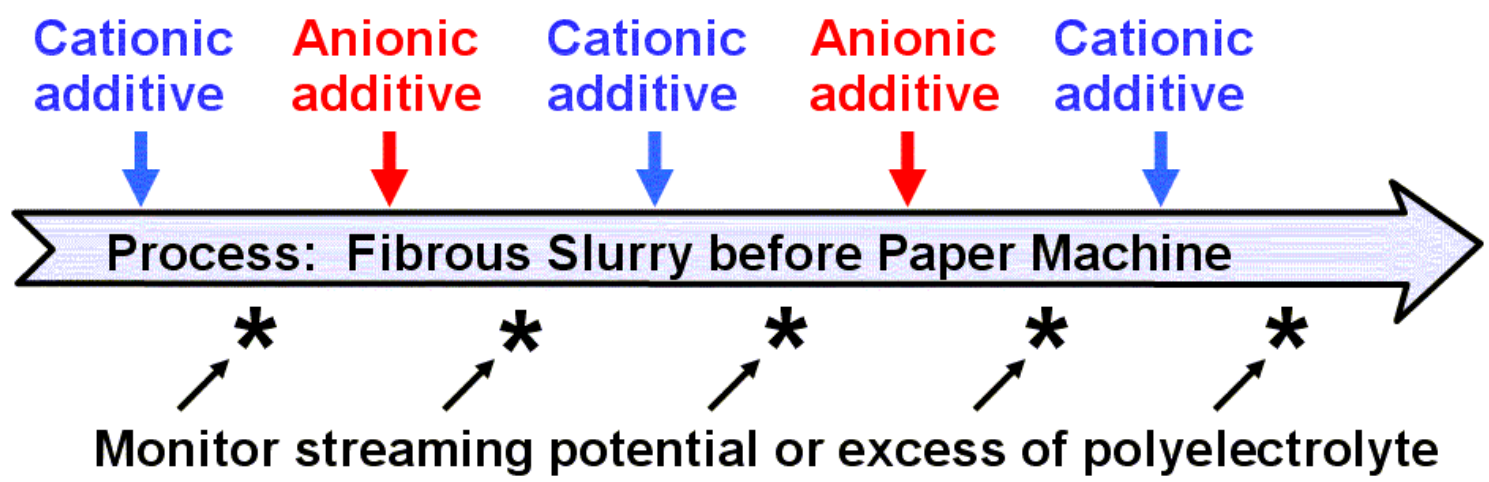

Fig. 8. Concept of how self-assembled multi-layers of dry-strength polymers might be applied to papermaking fibers in a continuous process, with online control of dosages and optimization of electrokinetic properties. This concept requires that adequate adsorption efficiency can still be achieved in each successful step, even though there cannot be any large excesses of polyelectrolytes used, in the absence of rinsing steps.

Let's assume, for the moment, that future studies show that it is indeed feasible to increase paper strength by "one pot" successive treatments with alternating polyelec- 
trolytes, without the use of rinsing steps. A big challenge, then, will be to fine-tune the amounts of added polyelectrolyte in each step. Too little polyelectrolyte would be considered undesirable, since a strong reversal of net surface change is required at each step, in order to render the surface attractive to the subsequent, oppositely charged layer. Too much polyelectrolyte would be considered undesirable, since the excess of unadsorbed polyelectrolyte would be subject to uncontrolled complexation with the next oppositely charged polyelectrolyte to be added, before the latter has a chance to reach the fiber surfaces. Though polyelectrolyte complexes appear to have a promising role to play with respect to development of dry strength in paper (Lofton et al. 2005), such interactions would defeat the goal of achieving multilayer self-assembly.

Fortunately, there are two parallel electrokinetic methods that hold promise for monitoring and controlling levels of polyelectrolyte addition, in order to achieve a controlled one-pot multilayer assembly, as just described. One such method involves titration with a highly charged polyelectrolyte in order to determine the net colloidal charge of the bulk solution, after a given treatment step. Automated systems are available for such tests, using streaming current measurements as an indication of the titration endpoint (Bley 1998; Hubbe and Chen 2004). As envisioned in Fig. 8, one would want to control the added amount, in each step, so that a very small controlled excess of that polymer remains in solution after mixing with the fibers. Fiber-pad streaming potential measurements are the other kind of electrokinetic measurement to be considered for this kind of application (Nazir 1994; Miyanishi 1995; Hubbe and Wang 2004). Such measurements sense the electrical potential adjacent to the surfaces of the fibers. Recently it was discovered that the sign of charge of the outer-most layers of cellulosic fibers can be detected by carrying out streaming potential measurements in the presence of aqueous solution having a low electrical conductivity (Hubbe et al. 2006a). Online equipment has been developed for continuous measurements of streaming potential in paper mills (Nazir 1994; Miyanishi 1995). In order to use such equipment for the purposes just described it would be necessary to modify the equipment so that the fiber slurry is first dewatered, then resuspended in low conductivity solution, then subjected to the automated zeta potential test (Hubbe et al. 2006a).

\section{Film Quality}

As noted by Linhart (2005), wet-end additives that are most promising in terms of dry-strength development also tend to form strong films, in cases where dilute aqueous polymeric solutions are applied to smooth substrates, followed by evaporation. This correlation suggests that the cohesive strength within the adhesive layers provided by dry-strength additives may be an important factor. In support of this view, Lertsutthiwong et al. (2002) attributed the good dry-strength performance of chitosan to the fact that it forms a good film. The authors stressed that chitosan has a compatible structure with cellulose, tending to promote efficient interdiffusion, essentially welding the fibers together upon drying of the paper.

Though issues related to the cohesive strength of the "glue" used to hold papermaking fibers together has received relatively little attention until recently (Pelton 2004; Linhart 2005), there is reason for concern. The cohesion within a layer of polyelectrolytes and other substances at a fiber surface can be only as strong as its 
weakest point. Processes associated with the flocculation interactions of polymers (Fleer et al. 1993; Kötz 1993; Mende et al. 2002) might be expected to produce non-uniform distributions of density, including areas of weakness in films. In addition, it is known that cracks that develop in an adhesive film as a result of the drying process can have a dominant effect on failure of glue joints (Veselovsky and Kestelman 2002).

As noted by Helle (1965), in considering the tensile strength of paper it is often more useful to think in terms of a rope, rather than thinking in the terms of an isotropic solid material. Rope's toughness, flexibility, and high tensile strength are due in part to the non-rigid association between adjacent strands. Likewise, it would appear important that inter-fiber contacts in paper be designed with an appropriate amount of compliance, depending on requirements for the paper grade. Leech (1954) proposed that gums can increase paper strength by increasing the flexibility of bonded areas between fibers. On the other hand, it would make sense that stiff paper products can benefit from the use of additives such as starch (Retulainen and Nieminen 1996), which tend to produce relatively stiff films upon drying. This issue is not settled, however, since more recent work by Yamauchi and Hatanaka (2002) suggested that wet-end starch increases the ability of paper to withstand tensile strains without breaking; this observation might be taken as evidence of increased compliance within the bonded areas. One can expect that there are many additional opportunities to match the cohesive and viscoelastic behavior of dry-strength additives, in their solid form, relative to paper performance.

Let us assume that high tensile strength that can be achieved in a flexible structure that allows some internal movement among the component members. As noted by Van den Akker (1969), most of the energy that is consumed during the tensile breakage of paper is expended in the flexing of fibers. Consistent with this idea it has been found that superior dry tensile strength can be achieved if the furnish is fractionated, the agent added to the fiber fraction, and then the furnish components are recombined (Strazdins 1980; Stratton 1989). By restricting the effects of the strength additives mainly to the crossingpoints of fibers, at locations not covered by fines, a certain level of slippage is possible within the paper structure, helping to distribute loads. Despite the promising nature of such results, no published accounts were found describing industrial applications of fractionation, followed by selective addition of dry-strength agents. It appears likely that the lack of commercial interest is due to the relatively high costs associated with fiber fractionation. What is needed, it seems, is a chemical-based way to achieve similar objectives, a kind of "spot welding" within the paper sheet, rather than uniformly increasing bonding over all of the contacting surfaces. This, in addition to many other of the ideas presented in this review, imply that there will be plenty of interesting questions to occupy paper scientists for a long time to come.

\section{REFERENCES CITED}

Abson, D., and Brooks, D. F. (1985). "Wet-end behavior of dry strength additives," Tappi J. 68(1), 76-78. 
Advincula, R., Aust, E., Meyer, E., and Knoll, W. (1996). "In situ investigations of polymer self-assembly solution adsorption by surface plasmon spectroscopy," Langmuir 12(15), 3536-3540.

Akagane, K., Allan, G. G., Dutkeiwicz, J., Liu, T. M., and Palicka, J. (1979). "Fiber surface modification. 20. Multicenter hydrogen bonding, a new concept in adhesion," Paperi Puu 61(10), 624-628, 634.

Akitt, J. W., Greenwood, N. N., Khandelwal, B. L., and Lester, G. D. (1972). “27 A1 nuclear magnetic resonance studies of the hydrolysis and polymerization of hexaaquo-aluminum(III) cation" J. C. S. Dalton Trans. (5), 604-610.

Alince, B. (1975). "Development of paper tensile strength by periodate oxidation," Svensk Papperstidning 78(7), 253-257.

Alince, B., Lebreton, R., and St.-Amour, S. (1990). "Using cationic starch in filled papers," Tappi J. 73(3), 191-193.

Allan, G. G., Delgado, E., and Lopez-Dellamary, F. (1993). "New interfiber system for paper involving zwitterions," in Baker, C. F., ed., Products of Papermaking, Trans. $10^{\text {th }}$ Fund. Res. Symp., Pira, Leatherhead, UK, Vol. 2, 1101-1138.

Allan, G. G., and Reif, W. M. (1977). "Fiber surface modification. The stereotopochemistry of ionic bonding in paper," Svensk Papperstidn. 80(6), 173-177.

Back, E. (1987). "Using the wet press to optimize paper properties," Paper Technol. Ind. 8(3), 454-455, 458-459.

Baker, C. F. (1995). "Good practice for refining the types of fiber found in modern paper furnishes," Tappi J. 78(2), 147-153.

Barzyk, D., Page, D. H., and Ragauskas, A. (1997). "Acidic group topochemistry and fiber-to-fiber specific bond strength," J. Pulp Paper Sci. 23(2), J59-J61.

Batchelor, W., and He, J. (2005). "A new method for determining the relative bonded area," Tappi J. 4(6), 23-28.

Beaudoin, R., Gratton, R., and Turcotte, R. (1995). "Performance of wet-end cationic starches in maintaining good sizing at high conductivity levels in alkaline fine paper," J. Pulp Paper Sci. 21(7), J238-J243.

Beghello, L., Long, L. Y., and Eklund, D. (1997). "Laboratory study on carboxymethylcellulose as a wet-end additive in paperboard making," Paperi Puu 79(1), 55-57.

Bhardwaj, N. K., Bajpai, P., and Bajpai, P. K. (1997). "Enhancement of strength and drainage of secondary fibers," Appita J. 50(3), 230-232.

Bletzinger, J. C. (1943). "Effect of acetylation on water-binding properties of cellulose," Ind. Eng. Chem. 35(4), 474-480.

Bley, L. (1998). "Latest experiences of on-line charge measurements: A process control concept." Pulp Paper Can. 99(5), 51-55.

Bottero, J.-Y., and Fiessinger, F. (1989). "Aluminum chemistry in aqueous solution," Nordic Pulp Paper Res. J. 4(2), 81-89.

Brandal, J., and Lindheim, A. (1966). "The influence of extractives in groundwood pulp on fiber bonding," Pulp Paper Mag. Can. 67(10), T481-T435.

Brouwer, P. H. (1997). "Anionic wet-end starch in, size-press out?," Wochenbl. Papierfabr. 125(9), 928-937.

Campbell, W. B. (1947). "Academic aspects of paper stock preparation," Tech. Assoc. Papers 30(6), 177-180. 
Campbell, W. B. (1959). “The mechanism of bonding," Tappi 42(12), 999-1001.

Carlsson, G., Lindström, T., and Söremark, C. (1977). "The effect of cationic polyacrylamides on some dry strength properties of paper," Svensk Papperstidn. 80(6), 173177.

Carr, M. E., Hamerstrand, G. E., Hofreiter, B. T., and Russell, C. R. (1977). “A polysalt complex for wet-end addition," Tappi 60(12), 148-149.

Carr, M. E., Hofreiter, B. T., Hamerstrand, G. E., and Russell, C. R. (1974). "Interpolymer from starch xanthate and polyamide-polyamine-epichlorohydrin resin in linerboard and newsprint," Tappi 57(10), 127-129.

Caruso, F., Lichtenfeld, M., Donath, E., and Möhwald, H. (1999). "Investigation of electrostatic interaction in polyelectrolyte multilayer films: Bonding of anionic fluorescent probes to layers assembled onto colloids," Macromolecules 32(7), 2317-2328.

Chan, L. L. (1976). "Dry strength resins: Useful tools for paper making," Pulp Paper Can. 77(6), T93-T95.

Clark, J. d'A. (1973). "Components of the strength qualities of pulps," Tappi 56(7), 122-125.

Clark, J. d'A. (1985a). "Bonding of cellulose surfaces," in Pulp Technology and Treatment for Paper, $2^{\text {nd }}$ Ed., Miller Freeman, San Francisco, Ch. 7, pp. 145-159.

Clark, J. d'A. (1985b). "Fibrillation and fiber bonding," in Pulp Technology and Treatment for Paper, $2^{\text {nd }}$ Ed., Miller Freeman, San Francisco, Ch. 8, pp. 160-180.

Conte, J. S., and Bender, G. W. (1992). "Softening and debonding agents," in Chemical Processing Aids in Papermaking: Practical Guide, K. J. Hipolit, ed., TAPPI Press, Atlanta, 167-177.

Corte, H., and Schaschek, H. (1955). "The physical nature of paper strength," Papier 9(21/22), 519-530.

Cramm, R. H., and Bibee, D. V. (1982). "The theory and practice of corona treatment to improve adhesion," Tappi 65(8), 75-78.

Crawford, R. A., and Flood, T. A. (1989). "Preliminary NMR study on structure of polyaluminum chloride," Proc TAPPI Papermakers Conf., TAPPI Press, Atlanta, 56-59.

Dalidowicz, P. C. (2000). "Drainage aids containing bound phosphorus," Proc. TAPPI Papermakers Conf., TAPPI Press, Atlanta, 119-123.

Davison, R. W. (1980). "Theory of dry strength development," in Reynolds, W. F., ed., Dry Strength Additives, TAPPI Press, Atlanta, Ch. 1, 1-31.

Davison, R. W., and Cates, R. E. (1975). "Electrokinetic effects in papermaking systems: Theory and practice," Paper Technol. Ind. 16(2), 107-114.

Decher, G. (1997). "Fuzzy nanoassemblies: Toward layered polymeric multicomposites," Science 227(5330), 1232-1237.

Decher, B., Hong, J. D., and Schmitt, J. (1992). "Buildup of ultrathin multilayer films by a self-assembly process: 3 . Consequently alternating adsorption of anionic and cationic polyelectrolytes on charged surfaces," Thin Solid Films 210/211(1-2), 831-835.

Dobrynin, A. V., Rubinstein, M., and Joanny, J.-F. (1997). "Adsorption of a polyampholyte chain on a charged surface," Macromolecules 30(15), 4332-4341.

Dubas, S. T., and Schlenoff, J. B. (1999). "Factors controlling the growth of polyelectrolyte multilayers," Macromolecules 32(24), 8153-8160. 
Duchesne, I., Daniel, G., Van Leerdam, G. C., and Basta, J. (2003). "Surface Chemical Composition and Morphology of ITC Kraft Fibers as Determined by XPS and FESEM,” J. Pulp Paper Sci. 29(3): 71-76.

Dugal, H. S., and Swanson, J. W. (1972). "Effect of polymer mannan content on the effectiveness of modified guar gum as a beater adhesive," Tappi 55(9), 1362-1367.

Dulemba, M., Qi, D., and Aravamuthan, R. (1999). "The effect of repeated drying and wetting on single fiber flexibility," Prog. Paper Recycling 9(1), 38-45.

Durand-Piana, G., Lafuma, F., and Audebert, F. (1987). "Flocculation and adsorption properties of cationic polyelectrolytes toward Na-montmorillonite dilute suspensions," J. Colloid Interface Sci. 119(2), 474-480.

Ecklund, D. E. (1989). "Review of surface application," in Fundamentals of Papermaking, C. F. Baker, ed., Mechan. Eng. Publ. Ltd., London, Vol. 2, 833-870.

Ehrnrooth, E., Htun, M., and de Ruvo, A. (1977). "Esterification as a means of improving the properties of once-dried fibers," Trans Symp. Fiber-Water Interactions in Papermaking, Oxford, British Paper and Board Makers Assoc., London, 899-915.

Ekevåg, P., Lindström, T., Gellerstedt, G., and Lindström, M. E. (2004). "Addition of carboxymethylcellulose to the kraft cook," Nordic Pulp Paper Res. J. 19(2), 200-207.

Eriksson, M., Notley, S. M., and Wågberg, L. (2005a). "The influence on paper strength properties when building multilayers of weak polyelectrolytes onto wood fibers," $J$. Colloid Interface Sci. 292(1), 38-45.

Eriksson, M., Pettersson, G., and Wågberg, L. (2005b). “Application of polymeric multilayers of starch onto wood fibers to enhance strength properties of paper," Nordic Pulp Paper Res. J. 20(3), 270-276.

Fält, S., and Wågberg, L. (2003). "Influence of electrolytes on the swelling and strength of kraft-liner pulps," Nordic Pulp Paper Res. J. 18(1), 69-73.

Farley, C. E. (1987). "Polyacrylamide wet and dry strength resins," TAPPI 1987 Advanced Topics in Wet End Chemistry Sem. Notes, TAPPI Press, Atlahta, 91-95.

Farley, C. E. (1997). "Factors influencing the rate of charge decay," Tappi J. 80(10), 177-183.

Fellers, C. (1983). "Edgewise compression strength of paper," in Mark and Murakami, eds., Handbook of Physical and Mechanical Testing of Paper and Paperboard, Vol. 1., Dekker, New York, Ch. 8, 349-383.

Fleer, G. J., Cohen-Stuart, M. A., Scheutjens, J. M. H. M., Cosgrove, T., and Vincent, B., eds. (1993). Polymers at Interfaces, Chapman and Hall, London, see 343-375.

Formento, J. C., Maximino, M. G., Mina, L. R., Srayh, M. I., and Martinez, M. J. (1994). "Cationic starch in the wet end: Its contribution to interfiber bonding," Appita 47(4), 305-308.

Fors, C. (2000). "The effect of fiber charge on web consolidation in papermaking," Licenciate Thesis, Royal Inst. Technol., Stockholm, Sweden.

Fowkes, F. M. (1983). "Acid-base interactions in polymer adhesion," in K. L. Mittal, ed., Physicochemical Aspects of Polymer Surfaces, Vol. 2, Penum Press, New York, 583-603.

Fujita M., and Harada, H. (2000). "Ultrastructure and formation of wood cell wall," in Wood and Cellulosic Chemistry, $2^{\text {nd }}$ Ed., D. N.-S. Hon and N. Shiraishi, eds., Dekker, New York, Ch. 1, 1-49. 
Fukunaga, Y. (1999). "New application method of dry strength agents by effective utilization of amphoteric polyacrylamide and aluminum sulfate," Proc. Japan TAPPI Ann. Mtg., 349-357.

Gardner, K. H., and Blackwell, J. (1974). "Structure of native cellulose," Biopolymers 13(10), 1975-2001.

Gärdlund, L., Forsström, J., Andreasson, B., and Wågbberg, L. (2005). "Influence of polyelectrolyte complexes on the strength properties of papers from unbleached kraft pulps with different yields," Nordic Pulp Paper Res. J. 20(1), 71-77.

Gärdlund, L., Wågbberg, L., and Gernandt, R. (2003). "Polyelectrolyte complexes for surface modification of wood fibers. 2. Influence of complexes on wet and dry strength of paper," Colloids Surf. A 218(1-3), 137-149.

Gaspar, L. A. (1982). "Intrinsic bonding of cationic starch and application of cationic starch with recycled fiber" Proc. TAPPI 1982 Annual Meeting, TAPPI Press, Atlanta, 89-93.

Gernandt, R., Wågberg, L., Gärdlund, L., and Dauzenberg, H. (2003). "Polyelectrolyte complexes for surface modification of wood fibers. 1. Preparation and characterization of complexes for dry and wet strength improvement of paper," Colloids Surf. A 213(1), 15-25.

Ghosh, A. K. (1994). "Enhancement of paper strength of container materials using wet end additives in an acidic system," Appita 47(3), 227-30, 237.

Glittenberg, D. (1993). "Starch alternatives for improved strength, retention, and sizing," Tappi J. 76(11), 215-219.

Glittenberg, D., Hemmes, J.-L., and Bergh, N.-O. (1994). "Cationic starches in systems with high levels of anionic trash," Paper Technol. 35(7), 18-27.

Glittenberg, D., Tippett, R. J., and Leonhardt, P. (2004). "Wet-end starches - Still up to date for high speed papermaking?" Paper Technol. 45(6), 27-33.

Goossens, J. W. S., and Luner, P. (1976). "Flocculation of microcrystalline cellulose suspensions with cationic polymers - Effect of agitation," Tappi 59(2), 89-94.

Goring, D. A. I., and Suranyi, G. (1969). "Improving bonding of cellulose and other polymers by surface treatment with a gas," Pulp Paper Mag. Can, 70(20), T390-T110.

Görres, J., Amiri, R., Wood, J. R., and Karnis, A. (1995). "The shear bond strength of mechanical pulp fibers," J. Pulp Paper Sci. 22(5), J161-J164.

Green, C. (2006). "Improved pulp evaluations using a combination of free and restrained drying of handsheets," BioResources 1(2), 174-175.

Greif, D. S., and Gaspar, L. A. (1980). "Cationic starch as a wet end additive," in W. F. Reynolds, ed., Dry Strength Additives, TAPPI Press, Atlanta, Ch. 4, 95-117.

Grignon, J., and Scallan, A. M. (1980). "Effect of pH and neutral salts upon the swelling of cellulose gels," J. Appl. Polymer Sci. 25(12), 2829-2843.

Gupta, B., and Scott, W. (1995). "Interactions between cationic starches and papermaking fibers: The effect of starch characteristics on fiber surface charge and starch retention," Proc. TAPPI 1995 Papermakers Conf., TAPPI Press, Atlanta, 85-95.

Gutmann, H., Nelson, W. J., and Yerke, J. F. (1993). "Rule 41 implications for linerboard producers," Tappi J. 76(1), 158-163. 
Harvey, R. D., Klem, R. E., Bale, M., and Hubbard, E. D. (1979). "Cationic starches in papermaking applications," 1979 Retention and Drainage Seminar Notes, TAPPI Press, Atlanta, 39-46.

Heath, D., Ernst, A. J., Hofreiter, B. T., Phillips, B. S., and Russell, C. R. (1974). "Flocculating agent - starch blends for interfiber bonding and filler retention: Comparative performance with cationic starches," Tappi 57(11), 109-111.

Heerman, M. L., Welter, S. R. and Hubbe, M. A. "Effects of high treatment levels in a dry-strength additive program based on deposition of polyelectrolyte complexes: How much glue is too much?" Tappi J. 5(6), 9-14.

Helle, T. (1965). "Fiber strength - bonding strength - paper strength," Norsk Skogind. 19(9), 359-363.

Hiemenz, P. C., and Rajagopalan, R. (1997). Principles of Colloid and Surface Science, $3^{\text {rd }}$ Ed., Dekker, New York.

Hipple, B. J. (1991). "Fine paper properties and the effects of wet-end starch when using deinked recycled fiber in an alkaline system," Tappi J. 74(5), 79-84.

Hofreiter, B. T. (1981). "Natural products for wet-end addition," in J. P. Casey, ed., Pulp and Paper Chemistry and Chemical Technology, Vol. III, Wiley-Interscience, $3^{\text {rd }}$ Ed., New York.

Hoogeveen, N. G., Cohen Stuart, M. A., Fleer, G. J., and Böhmer, G. J. (1999). "Formation and stability of multilayers of polyelectrolytes," Langmuir 12(15), 3675-3681.

Horn, D., and Melzer, J. (1975). "The effect of high molecular cationic dewatering aids on the electrokinetic properties of pulp," Papier 29(12), 534-541.

Horsey, E. F. (1947). "Sodium carboxymethylcellulose for papermaking," Tech. Assoc. Papers 30, 294-298.

Hostetler, R. E., and Swanson, J. W. (1974). "Diffusion into and adsorption of polyethylenimine on porous silica gel," J. Polymer Sci. 12(1), 29-43.

Howard, R. C., and Jowsey, C. J. (1989). "The effect of cationic starch on the tensile strength of paper," J. Pulp Paper Sci. 15(6): J225-J229.

Hubbe, M. A. (2005). "Dry-strength development by polyelectrolyte complex deposition onto non-bonding glass fibers," J. Pulp Paper Sci. 31(4), 159-166.

Hubbe, M. A., and Chen, J. (2004). "Charge-related measurements - A Reappraisal. Part 1. Streaming current," Paper Technol. 45(8), 17-23.

Hubbe, M. A., Jackson, T. L., and Zhang, M. (2003a). "Fiber surface saturation as a strategy to optimize dual-polymer dry strength treatment," Tappi J. 2(11), 7-12.

Hubbe, M. A., Moore, S. M., and Lee, S. Y. (2005). "Effects of charge ratios and cationic polymer nature on polyelectrolyte complex deposition onto cellulose," Ind. Eng. Chem. Res. 44(9), 3068-3074.

Hubbe, M. A., Rojas, O. J., Lee, S. Y., Park, S., and Wang, Y. (2006b). "Distinctive electrokinetic behaviour of nanoporous silica particles treated with cationic polyelectrolytes," Colloids Surf. A, in print, available online.

Hubbe, M. A., Rojas, O. J., Lucia, L. A., and Jung, T. M. (2006a). "Consequences of the nanoporosity of cellulosic fibers on their streaming potential and their interactions with cationic polyelectrolytes," Cellulose, accepted.

Hubbe, M. A., Rojas, O. J., Sulić, N., and Sezaki, T. (2006c). "Unique Behaviour of Polyampholytes as Dry-Strength Additives," Appita J., accepted. 
Hubbe, M. A., Venditti, R. A., Barbour, R. L., and Zhang, M. (2003b). "Changes to unbleached kraft fibers due to drying and recycling," Prog. Paper Recycling 12(3), 11-20.

Hubbe, M. A., Wagle, D. G., and Ruckel, E. R. (1999). "Method for increasing the strength of a paper or paperboard product," U.S. Patent 5,956,180.

Hubbe, M. A., and Wang, F. (2004). "Charge-related measurements - A reappraisal. Part 2: Fiber-pad streaming potential," Paper Technol. 45(9), 27-34.

Ingmanson, W. L., and Thode, E. F. (1959). "Factors contributing to the strength of a sheet of paper. II. Relative bonded area," Tappi 42(1), 83-93.

Jayme, G. and Büttel, H. (1968). "The determination and meaning of water retention value (WRV) of various bleached and unbleached cellulosic pulps," Wochenbl. Papierfabr. 96(6), 180-187.

Jayne, J. E., Tongren, J. C., and Jackson, D. T. (1950). "Use of beater and headbox additives for the improvement of sheet characteristics," Tappi 33(1), 32-35.

Kadla, J. F., and Gilbert, R. D. (2000). "Cellulose structure: A review," Cellulose Chem. Technol. 34(3-4), 197-216.

Kajanto, I. (1998). "Structural mechanics of paper and board," in Paper Physics, K. Niskanen, ed., Fapet Oy, Helsinki, Ch. 6, 192-221.

Kang, T., Paulapuro, H., and Hiltunen, E. (2004). "Fracture mechanism in interfiber bond failure - microscopic observations," Appita J. 57(3), 199-203.

Kekkonen, J., Lattu, H., and Stenius, P. (2001). "Adsorption kinetics of complexes formed by oppositely charged polyelectrolytes," J. Colloid Interface Sci. 234(2), 384-392.

Ketola, H., and Andersson, T. (1999). "Dry-strength additives," in L. Neimo, ed., Papermaking Chemistry, Papermaking Sci. Tech. Ser. 4, Fapet Oy, Helsinki, 269-287.

Keothe, J. L., and Scott, W. E. (1993). "Polyelectrolyte interactions with papermaking fibers: The mechanism of surface-charge decay," Tappi J. 76(12), 123-133.

Koetse, M., Laschewsky, A., Jonas, A. M., and Wagenknecht, W. (2002). "Influence of charge density and distribution on the internal structure of electrostatically selfassembled polyelectrolyte films," Langmuir 18(5), 1655-1660.

Koljonen, K., Vainio, A., Hiltunen, E., Laine, J., and Stenius, P. (2003). "The effect of polyelectrolyte adsorption on the strength properties of paper made from mixtures of mechanical and chemical pulps," $5^{\text {th }}$ International Paper and Coating Chemistry Symp., Proc., June 16-19, 2003, Montreal, Canada, TAPPI Press, Atlanta, 223-227.

Kötz, J. (1993). "Phase behaviour of polyanions-polycation aggregates and possibilities of utilization," Nordic Pulp Paper Res. J. 8(1), 11-14.

Kunnas, L., Lehtinen, J., Paulapuro, H., and Kiviranta, A. (1993). "The effect of Condebelt drying on the structure of fiber bonds," Tappi J. 76(4), 95-104.

Laine, J., Lindström. T., Glad-Nordmark, G., et al. (2000). "Studies on topochemical modification of cellulosic fibers. Part 1. Chemical conditions for the attachment of carboxymethyl cellulose onto fibers," Nordic Pulp Paper Res. J. 15(5), 520-526.

Laine, J., Stenius, P., Suurnäkki, A., and Claesson, P. (1997). "The effect of wood components on the adhesive properties of cellulosic materials," ISWPC; $9^{\text {th }}$ Int'l. Symp. Wood Pulping Chem., Montreal, 1997.

Leech, H. J. (1954). "An investigation of the reasons for increase in paper strength when locust bean gum is used as a beater adhesive," Tappi 37(8), 343-349. 
Lertsutthiwong, P., Chandrkrachang, S., Nazhad, M. M., and Stevens, W. F. (2002). "Chitosan as a dry strength agent for paper," Appita J. 55(3), 208-212.

Lindström, T., and Florén, T. (1984). "The effects of cationic starch wet end addition on the properties of clay filled papers," Svensk Papperstidn. 87(12), R99-R104.

Lindström, T., and Kolman, M. (1982). "The effect of $\mathrm{pH}$ and electrolyte concentration during beating and sheet forming on paper strength," Svensk Papperstidn. 85(15), R140-R145.

Lindström, T., and Söremark, C. (1975). "Zeta potential measurement in the manufacture of paper," Papier 29(12), 519-525.

Lindström, T., Wågberg, L., and Larsson, T. (2005). "On the nature of joint strength in paper - A review of dry and wet strength resins used in paper manufacturing," Proc. $13^{\text {th }}$ Fundamental Research Symp., Cambridge, Pira Intl., Leatherhead, Surrey, UK.

Linhart, F. (2005). "Some thoughts on the mode of action of paper strength agents," Wochenbl. Papierfabr. 133(11/12), 662-672.

Linhart, F., Horn, D., Eisenlauer, J., and Hemel, R. (1987). "Monitoring and control of formation by means of a fiber optic flocculation sensor," Wochenbl. Papierfabr. 115(8), 331-338.

Linke, W. F. (1968). "Retention and bonding of synthetic dry strength resins," Tappi 51(11), 59A-65A.

Lofton, M. C., Moore, S. M., Hubbe, M. A., and Lee, S. Y. (2005). "Polyelectrolyte complex desposition as a mechanism of paper dry-strength development," Tappi J. 4(9), 3-7.

Lorenčak, P., Strange, A., Nießner, M., and Esser, A. (2000). "Polyvinylamine - A new polymer for increasing paper strength," Wochenbl. Papierfabr. 128(1/2), 14-18.

Lowe, A. B., Billingham, N. C., and Armes, S. P. (1999). "Synthesis and properties of low-polydispersity poly(sulfopropylbetaine)s and their block copolymers," Macromolecules 32(7), 2141-2148 (1999).

Lyne, L. M., and Gallay, W. (1954). "Studies in the fundamentals of wet web strength," Tappi 37(12), 698-704.

Mahltig, B., Walter, H., Harrats, C., Müller-Buschbaum, P., Jérôme, R., and Stamm, M. (1999). Phys. Chem. Chem. Phys. 1(17), 3853-3856.

Mann, J., and Marrinan, H. J. (1958). "Polarized infrared spectra of cellulose-1," J. Polymer Sci. 27(115), 595-596 (1958).

Malton, S., Kuys, K., Parker, I., and Vanderhoek, N. (1998). "Adsorption of cationic starch on eucalypt pulp fibers and fines," Appita J. 51(4), 292-298.

Marton, J. (1980). "The role of surface chemistry in fines - cationic starch interactions," Tappi 63(4), 87-91.

Marton, J., and Marton T. (1976). "Wet end starch: Adsorption of starch on cellulosic fibers," Tappi 59(12), 121-124.

Mason, S. G. (1950). "The flocculation of pulp suspensions and the formation of paper," Tappi 33(9), 440-444.

Mathur, G. M., Mahajan, S., Unnikikshanan, K. P., and Sharma, Y. K. (1987). "Studies on sheet pressing. 1. Effect of intensity of pressure during wet pressing on physical properties of standard test sheets made from short fibers," IPPTA 4(3 Suppl.), 23-33. 
Maximova, N., Laine, J., and Stenius, P. (2005). "Adsorption of lignin-cationic starch complexes on cellulose fibers and their effect on sheet properties," Paperi Puu 87(3), 176-182.

Mayhood, C. H., Jr., Kallmes, O. J., and Cauley, M. M. (1962). “The mechanical properties of paper. Part II: Measured shear strength of individual fiber to fiber contacts," Tappi 45(1), 69-73.

McKenzie, A. W. (1964). "The structure and properties of paper. 16. Relationship between starch dispersion and retention, degree of beating and paper strength ," Appita 18(1), 4-15.

McKenzie, A. W. (1984). "The structure and properties of paper. Part XXI: The diffusion theory of adhesion applied to interfiber bonding," Appita 37(7), 580-583.

McKenzie, A. W. (1987). "The effect of esterification on papermaking fibers - a reappraisal," Appita 40(4), 273-278.

McQueary, R. T. (1990). "Wet end waxy amphoteric starch impacts drainage, retention, and strength," Proc. TAPPI 1990 Papermakers Conf., TAPPI Press, Atlanta, 137-142.

Mende, M., Petzold, G., and Buchhammer, H.-M. (2002). "Polyelectrolyte complex formation between poly(diallyldimethyl-ammonium chloride) and copolymers of acrylamide and sodium-acrylate," Colloid Polymer Sci. 280(4), 342-351.

Merle, L., and Merle, Y. (1982). "Synthetic polyampholytes. 2. Sequence distribution in methacrylic acid-(dimethylamine)ethyl methacrylate copolymers by ${ }^{13} \mathrm{C} N M R$ spectroscopy," Macromolecules 15(2), 360-366.

Minor, J. L., Atalla, R. H., and Harten, T. M. (1991). "Improving interfiber bonding of recycled fibers," Proc. 1991 Recycling Forum, 115-122.

Miyanishi, T. (1995). "On-line zeta potential analyses of a fine paper machine and a newsprint paper machine," Tappi J. 78(3), 85-91.

Mobarak, F., El-Ashmawy, C. S., and Fahmy, Y. (1973). "Hemicelluloses as additive in papermaking. Part II. The role of added hemicellulose, and hemicellulose in situ on paper properties," Cellulose Chem. Technol. 7, 325-335.

Modig, G., Nilsson, P. O., and Wahlund, K. G. (2006). "Influence of jet-cooking temperature and ionic strength on size and structure of cationic potato amylopectin starch as measured by asymmetrical flow filed-flow fractionation multi-angle light scattering," Starch-Stärke 58(2), 55-65.

Moeller, H. W. (1966). "Cationic starch as a wet-end strength additive," Tappi 49(5), 211-214.

Moss, P. A., and Retulainen, E. (1997). "The effect of fines on fiber bonding: Crosssectional dimensions of TMP fibers at potential bonding sites," J. Pulp Paper Sci. 23(8), J382-J388.

Nagata, T. (1991). "Recent advances of paper strengthening agent: New mechanism of dry-strength development; Concept of anionic and cationic polyacrylamide mixing system," Jpn. Tappi J. 45(2), 245-249.

Nanko, H., and Ohsawa, J. (1989). "Mechanisms of fiber bond formation," in Fundamentals of Papermaking, Proc. Fundamental Res. Symp, Vol. 2, Waveney Print Services, Suffolk, UK, 783-830.

Nanko, H., Ohsawa, J., and Okagawa, A. (1989). "How to see interfiber bonding in paper sheets," J. Pulp Paper Sci. 15(1), J17-J23. 
Nazhad, M. M., and Pazner, L. (1994). "Fundamentals of strength loss in recycled paper," Tappi J. 77(9), 171-179.

Nazhad, M. M., Harris, E. J., Dodson, C. T. J., and Kerekes, R. J. (2000). "The influence of formation on tensile strength of paper made from mechanical pulps," Tappi J. 83(112), 63 (digital document).

Nazir, B. A. (1994). "An on-line streaming potential meter (SPM) - Wet-end applications," Paper Technol. 35(3), 28-35.

Nealey, L., Hamada, M., and Kimura, T. (1989). "Some factors affecting strength enhancement by a polyacrylamide dual polymer system," Proc. TAPPI 1989 Papermakers Conf., TAPPI Press, Atlanta, 261-268.

Neuman, R. D. (1993). "Surface force measurement in papermaking systems," in Products of Papermaking, Trans. $10^{\text {th }}$ Fund. Res. Symp., Pira, Leatherhead, UK, Vol. 3, 969-1021.

Nissan, A. H., Byrd, V. L., Batten, G. L., and Ogden, R. W. (1985). "Paper as an Hbond dominated solid in the elastic and plastic regimes," Tappi J. 68(9), 118-124.

Nissan, A. H., and Sternstein, S. S. (1964). "Cellulose-fiber bonding," Tappi 47(1), 1-6.

Obermanns, H. E. (1936). "A study of the effect of hemicelluloses on the beating and strength of pulps," Paper Trade J. TAPPI Sec. 103(8), T109-T117.

Olsson, C., Frigard, T., Andersson, R., and Hermansson, A. M. (2003). "Effects of amylopectin structure and molecular weight on microstructural and rheological properties of mixed beta-lactoglobulin gels," Biomacromol. 4(5), 1400-1409.

Paavilainen, L. (1993). "Conformability, flexibility and collapsibility of sulfate pulp fibers," Paperi Puu 75(9-10), 689-702.

Page, D. H. (1960). "Fiber-to-fiber bonds. Part 1 - A method for their direct observation," Paper Technol. 1(4), 407-411, T165-T169.

Page, D. H. (1969). "A Theory for the Tensile Strength of Paper," Tappi 52(4), 674-681.

Page, D. H., and Tydeman, P. A. (1962). "A new theory of the shrinkage, structure, and properties of paper," in Formation and Stucture of Paper, F. Bolam, ed., Tech. Sect. British Paper and Board Makers' Assoc., London, Vol. 1, 397-425.

Park, S.-B., and Tanaka, H. (1998). "Effects of charge densities of cationic polyacrylamides on strength properties of handsheets," Mokusai Gakkaishi 44(3), 199-204.

Parsons, S. R. (1942). "Optical characteristics of paper as a function of fiber classification," Paper Trade J. 115(25), 314-322.

Paul, D. R., and Barlow, J. W. (1982). In Polymer Compatibility and Incompatibility, Principles and Practices, K. Solc., ed., Hardwood Academic Publ., 1.

Paulapuro, H. V., and Thorp, B. A. (1983). "Effect of pulp and papermaking variables on linerboard ring crush," Pulp Paper 57(11), 142-145.

Pelton, R. (1993). "A model of the external surface of wood pulp fibers," Nordic Pulp Paper Res. J. 8(1), 113-119.

Pelton, R. (2004). "On the design of polymer for increased paper dry strength - A review," Appita J. 57(3), 181-190.

Pelton, R., Zhang, J., Wågberg, L, and Rundlöf, M. (2000). "The role of surface polymer compatibility in the formation of fiber/fiber bonds in paper," Nordic Pulp Paper Res. J. 15(5), 400-406. 
Pelton, R., Zhang, J., Chen, N., and Moghaddamzadeh, A. (2003). "The influence of dextran molecular weight on the dry strength of dextran-impregnated paper," Tappi J. 2(4), 15-18.

Penniman, J. G. (1992). "Comparison of pulp pad streaming potential measurement and mobility measurement," Tappi J. 75(8), 111-115.

Pierce, F. T. (1930). "The mechanism of growth in the cotton hair," Trans. Faraday Soc. 26, 809-813.

Poffenberger, C., Deae, Y., and Zeman, W. (2000). "Novel hydrophilic softeners for tissue and towel applications," Proc. TAPPI 2000 Papermakers Conf., TAPPI Press, Atlanta, 85-93.

Ratliff, F. T. (1949). "The possible correlation between hemicelluloses and the physical properties of bleached kraft pulps," Tappi 32(8): 357-367.

Reif, W. M. (1972). "The utilization of ionic bonds in the development of paper strength," Proc. TAPPI 1972 Papermakers Conf., TAPPI Press, Atlanta, 47-61.

Retulainen, E. (2003). "Condebelt press drying and sustainable paper cycle," Paperi Puи 85(6), 329-333 (2003).

Retulainen, E., and Nieminen, K. (1996). "Fiber properties as control variables in papermaking? Part 2. Strengthening interfiber bonds and reducing grammage," Paperi Puu 78(5), 305-312.

Retulainen, E., Nieminen, K., and Nurminen, I. (1993). "Enhancing strength properties of kraft and CTMP fiber networks," Appita 46(1), 33-38.

Retulainen, E., and Nurminen, I. (1993). "Effects of sodium chlorite delignification and alkaline extraction on bonding of CTMP fibers and the efficiency of dry strength additives," Paperi Puu 75(7), 499-504.

Reynolds, W. F. (1961). "Some recent research on Accostrength Resin 2386," Tappi 44(2), 177A-179A.

Reynolds, W. F. (1980). "Acrylamide-based polymers for dry strength improvement of paper," in Dry Strength Additives, W. F. Reynolds, ed., TAPPI Press, Atlanta, Ch. 6, 125-148.

Reynolds, W. F., and Wasser, R. B. (1980). "Dry-strength resins," in Pulp and Paper Chemistry and Chemical Technology, J. P. Casey, ed., $3^{\text {rd }}$ Ed., Wiley-Interscience, New York, Vol. 3, Ch. 13, 1447-1474.

Roberts, J. C. (1992). "Succinylation of pulps," Proc. The Chemistry of Papermaking, Pira Intl., Leatherhead, UK, Paper 8.

Roberts, J. C., Au, C. O., Clay, G. A., and Lough, C. (1986). "The effect of C ${ }^{14}$-labelled cationic and native starches on dry strength and formation," Tappi J. 69(10), 88-93.

Roberts, J. C., Au, C. O., Clay, G. A., and Lough, C. (1987). "A study of the effect of cationic starch on dry strength and formation using C14 labeling," J. Pulp Paper Sci. 13(1), J1-J5.

Robinson, J. V., Jr. (1980). "Fiber bonding," in Pulp and Paper Chemistry and Chemical Technology, J. P. Casey, ed., $3^{\text {rd }}$ Ed., Vol. II, Ch. 7, 915-961.

Sachs, I. B., and Kuster, T. A. (1980). "Edgewise compression failure mechanism of linerboard observed in a dynamic mode," Tappi 63(10), 69-73.

Saito, T., and Isogai, A. (2005). "A novel method to improve wet strength of paper," Tappi J. 4(3), 3-8. 
Scallan, A. M., and Tigerström, A. C. (1992). "Swelling and elasticity of the cell walls of pulp fibers," J. Pulp Paper Sci. 18(5), J188-J193.

Schneider, J., and Huang, F. (1993). "The use of anionic modified potato starch for ionic charge control," Proc. TAPPI 1993 Papermakers Conf., TAPPI Press, Atlanta, 599612.

Seth, R. S. (2003). “The measurement and significance of fines," Pulp Paper Can. 104(2), 41-44.

Seth, R. S., Soszynski, R. M., and Page, D. H. (1979). "Intrinsic edgewise compression strength of paper," Tappi 62(12), 97-99.

Sezaki, T., Hubbe, M. A., Heitmann, J. A., Argyropoulos, D. S., and Wang, X. (2006a). "Colloidal effects of acrylamide polyampholytes. Part 1. Electrokinetic behavior," Colloids and Surfaces A. 281(1-3), 74-81.

Sezaki, T., Hubbe, M. A., Heitmann, J. A., Argyropoulos, D. S. (2006b). "Colloidal effects of acrylamide polyampholytes. Part 2. Adsorption onto cellulosic fibers," Colloids and Surfaces A, 289(1-3), 89-95.

Slater, P. F. (2003). "Shoe press dewatering, methods to increase efficiency and water removal in the press section," TAPPI Spring Tech. Conf., TAPPI Press, Atlanta, 807813.

Smith, D. C. (1992). "Chemical additives for improved compression strength of unbleached board," Proc. TAPPI 1992 Papermakers Conf., TAPPI Press, Atlanta, 393-404.

Song, J., Wang, Y., Hubbe, M. A., Rojas, O. J., Sulic, N. R., Sezaki, T. (2006). "Charge and the dry-strength performance of polyampholytes. Part 1. Handsheets and bulk vscosity," J. Pulp Paper Sci., accepted.

Spence, G. G. (1999). "Application of wet- and dry-strength additives," Wet- and DryStrength Additives - Application, Retention, and Performance, TAPPI Press, Atlanta, 19-47.

Stone, J. E., and Scallan, A. M. (1966). "Influence of drying on the pore structures of the cell wall," in Consolidation of the Paper Web, F. Bolam, ed., Tech. Sec. Brit. Paper and Board Makers Assoc., London, Vol. 1, 145-174.

Stratton, R. A. (1989). "Dependence of sheet properties on the location of adsorbed polymer," Nordic Pulp Paper Res. J. 4(2), 104-112.

Stratton, R. A., and Colson, N. L. (1993). "Fiber wall damage during bond failure," Nordic Pulp Paper Res. J. 8(2), 245-249, 257.

Strazdins, E. (1977). "Optimization of the papermaking process by electrophoresis," Tappi 60(7), 113-114.

Strazdins, E. (1980). "New approaches towards optimizing dry strength of waste paper containing stock furnishes," Papier 34(10A), V49-V55.

Strazdins, E. (1984). "Chemical aids can offset strength loss in secondary fiber furnish use," Pulp Paper 58(3), 73-77.

Strazdins, E. (1989). "Theoretical and practical aspects of alum use in papermaking," Nordic Pulp Paper Res. J. 4(2), 128-134.

Strazdins, E. (1994). "Application of electrokinetics in optimization of wet-end chemistry," in Wet-Strength Resins and the Application, L L. Chan, ed., TAPPI Press, Atlanta, 63-83. 
Swanson, J. W. (1950). "The effects of natural beater additives on papermaking fibers," Tappi 33(9), 451-462.

Swanson, J. W. (1956). "Beater adhesives and fiber bonding - The need for further research," Tappi 39(5), 257-270.

Swinkels, J. J. M. (1985). "Composition and properties of commercial native starches," Starch/Stärke 37(1), 1-5.

Tanaka, A., Hiltunen, E., Kettunen, H., and Niskanen, K. (2001). "Inter-fiber bonding effects of beating, starch, and filler," Nordic Pulp Paper Res. J. 16(4), 306-312.

Tatsumi, D., and Yamauchi, T. (1997). "Depth profile of paper additives within a pulp fiber," in The Fundamentals of Papermaking Materials, C. F. Baker, ed., Pira International, Leatherhead, Surrey, UK, Vol. 3., 789-814.

Thode, E., and Ingmanson, W. L. (1959). "Factors contributing to the strength of a sheet of paper. I. External specific surface and swollen specific volume," Tappi 42(1), 7483.

Thomas, T. R. (1999). Rough Surfaces, $2^{\text {nd }}$ Ed., Imperial College Press, London, 1999.

Tiberg, F., Daicic, J., and Fröberg, J. (2001). "Surface chemistry of paper," in Handbook of Applied Surface and Colloid Chemistry, K. Holmberg, ed., Wiley, New York, Ch. 7., 123-173.

Touchette, R. V., and Jenness, L. C. (1960). "Effect of surface active agents on drainage and physical strength properties of sulfite pulp," Tappi 43(5), 484-489.

Vainio, A., Paulapuro, H., Koljonen, K., and Laine, J. (2006). "The effect of drying stress and polyelectrolyte complexes on the strength properties of paper," J. Pulp Paper Sci. 32(1), 9-13.

Van den Akker, J. A. (1969). "An analysis of the Nordman 'bonding strength'," Tappi 52(12), 2386-2389.

Veselovsky, R. A., and Kestelman, V. N. (2002). Adhesion of Polymers, McGraw-Hill, New York.

Wågberg, L. (2000). "Polyelectrolyte adsorption onto cellulose fibers - A review," Nordic Pulp Paper Res. J. 15(5), 586-597.

Wågberg, L., Forsberg, S., Johansson, A., and Juntti, P. (2002). "Engineering of fiber surface properties by application of polyelectrolyte multilayer concept. Part 1. Modification of paper strength," J. Pulp Paper Sci. 28(7), 222-228.

Wågberg, L., Ödberg, L., and Glad-Nordmark, G. (1989). "Charge determination of porous substrates by polyelectrolyte adsorption. Part 1. Carboxymethylated, bleached cellulosic fibers," Nordic Pulp Paper Res. J. 4(2), 71-76.

Walecka, J. A. (1956). "An investigation of low degree of substitution carboxymethylcelluloses," Tappi 39(7), 458-463.

Wang, F., and Hubbe, M. A. (2002). "Charge properties of fibers in the paper mill environment. Part 1: Effect of electrical conductivity," J. Pulp Paper Sci. 28(10), 347-353.

Wang, Y., Hubbe, M. A., Sezaki, T., Wang, X., Rojas, O. J., and Argyropoulos, D. S. (2006a). "The role of polyampholyte charge density on its interactions with cellulose," Nordic Pulp Paper Res. J., accepted. 
Wang, Y., Hubbe, M. A., Rojas, O. J., Argyropoulos, D. S., Wang, X., and Sezaki, T. (2006b). "Charge and the dry-strength performance of polyampholytes. Part 3. Streaming potential analysis," Colloids Surf. A., accepted.

Watanabe, M., Gondo, T., and Kitao, O. (2004). Advanced wet-end system with carboxymethyl-cellulose," Tappi J. 3(5), 15-19.

Whistler, R. L., and Daniel, J. R. (1978). "Starch," in Kirk-Othmer Encyclopedia of Chemical Technology, $3^{\text {rd }}$ Ed., Wiley and Sons, New York, Vol. 21, 492-507.

Wielema, T. A., and Brouwer, P. H. (2003). "Paper performance and the increased use of fillers and pigments," Paper Technol. 44(9), 27-40.

Williamson, J. E. (1993). "Wet-laid systems," in Nonwovens - Theory, Process, Performance, and Testing, TAPPI Press, Atlanta, 139-152.

Worsick, A. (1994). "Developments in press technology," Paper Technol. 35(5), 30-35.

$\mathrm{Wu}, \mathrm{Z}$., Chen, S., and Lu, Y. (2004). "Investigation on mechanisms of the complexes of starch and poly(diallyldimethylammonium chloride) as a dry strength agent," Proc. $2^{\text {nd }}$ Intl. Symp. Technol. Pulping Papermaking Biotechnol. Fiber Plants, Nanjing Forestry Univ., 378-380.

Yamauchi, T., and Hatanaka, T. (2002). "Mechanism of paper strength development by the addition of dry strength resin," Appita J. 55(3), 240-243.

Ye, X.-C., Tanaka, H., and Sumimoto, M. (1990). "Effects of network-type polyacrylamides on the drainage and retention of wheat straw pulp," Mokuzai Gakkaishi 36(1), 64-68.

Yoshimoto, Y., Iwasa, Y., and Fujiwara, T. (2004). "Study on the mechanism of PAMs as dry strength agents," Proc. 2004 (71 $\left.{ }^{\text {st }}\right)$ Pulp Paper Res. Conf., 126-129.

Yoshizawa, J., Isogai, A., and Onabe, F. (1998). "Analysis and retention behavior of cationic and amphoteric starches on handsheets," J. Pulp Paper Sci. 24(7), 213-218.

Zauscher, S., and Klingenberg, D. J. (2000). "Surface and friction forces between cellulose surfaces measured with colloidal probe microscopy," Nordic Pulp Paper Res. J. 15(5), 459-468.

Zhang, J., Pelton, R., Wågberg, L., and Rundlöf, M. (2001). "The effect of molecular weight on the performance of paper strength-enhancing polymers," J. Pulp Paper Sci. 27(5), 145-151.

Zhang, J., Pelton, R., Wågberg, L., and Rundlöf, M. (2000). "The effect of charge density and hydrophobic modification on dextran-based paper strength enhancing polymers," Nordic Pulp Paper Res. J. 15(5), 440-445.

Zhang, M., Hubbe, M. A., Venditti, R. A., Heitmann, J. A. (2002). "Can recycled kraft fibers benefit from chemical addition before they are first dried?" Appita J. 55(2), 135-144).

Article submitted: June 29, 2006. Reviews obtained November 25, 2006; Published November 30, 2006 (no "peer-reviewed" label because editor is author). 